\title{
Patterns of Corporate Diversification in Canada: An Empirical Analysis
}

\author{
by \\ John R. Baldwin \\ Desmond Beckstead \\ Guy Gellatly \\ Alice Peters \\ No. 150 \\ 11F0019MPE No. 150 \\ ISSN: 1200-5223 \\ ISBN: 0-660-18188-6
Micro-Economic Analysis Division
24-B R.H. Coats Building
Ottawa, K1A 0T6
Statistics Canada \\ Facsimile Number: (613) 951-5403 \\ * (613) 951-8588 \\ Email: baldjoh@statcan.ca \\ ** (613) 951-6199 \\ Email: beckste@statcan.ca \\ ***(613) 951-3758
gellguy@ statcan.ca
****(613) 951-4086 \\ Email: alice.peters@statcan.ca
}

\section{June 2000}

Authors' names are listed alphabetically.

The opinions expressed herein are those of the authors and do not necessarily reflect the opinions of Statistics Canada. 


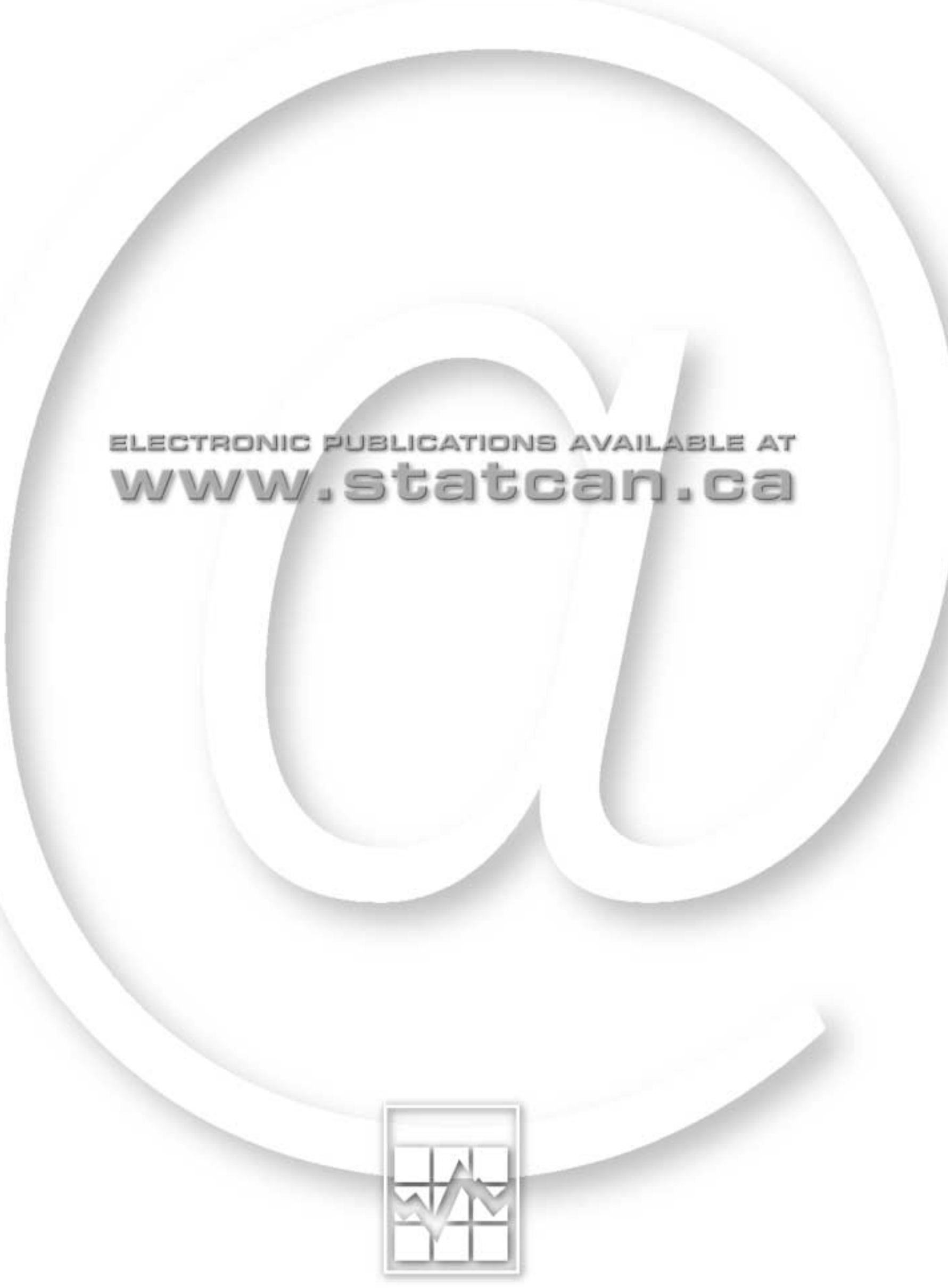




\section{Table of Contents}

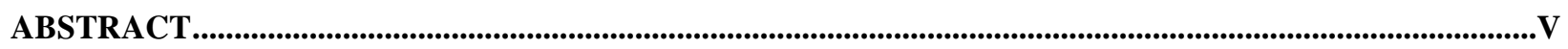

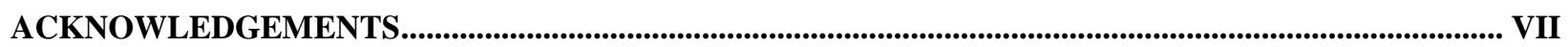

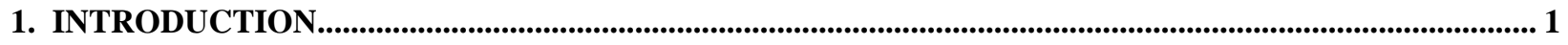

2. PERSPECTIVES ON CORPORATE DIVERSIFICATION …........................................................................... 3

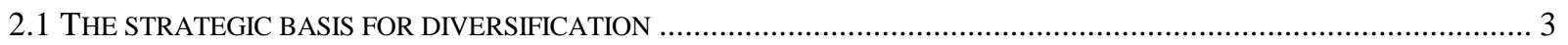

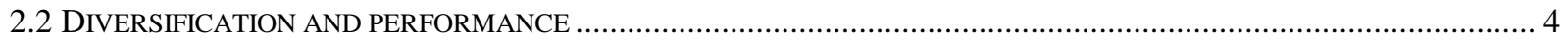

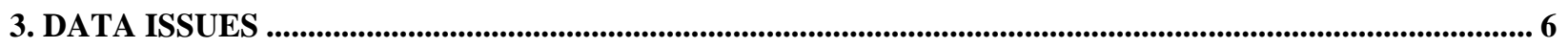

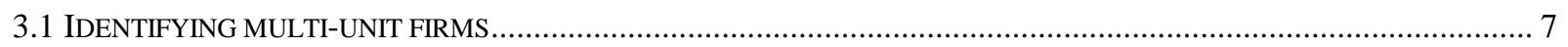

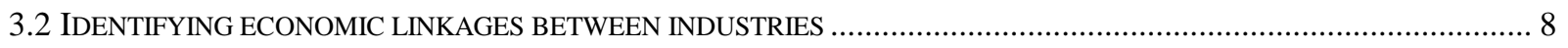

3.3 FORWARD AND BACKWARD LINKAGES BASED ON INPUT/OUTPUT TABLES .................................................... 9

3.4 RECONCILING INDUSTRY LINKAGES WITH OPERATING STRUCTURE .............................................................. 11

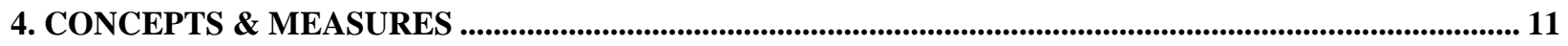

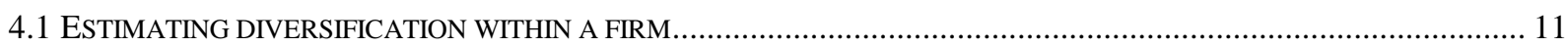

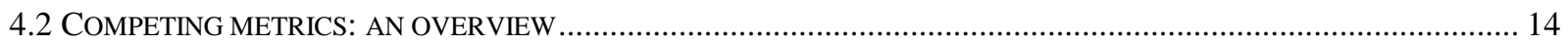

5. PATTERNS OF CORPORATE DIVERSIFICATION IN CANADA............................................................ 16

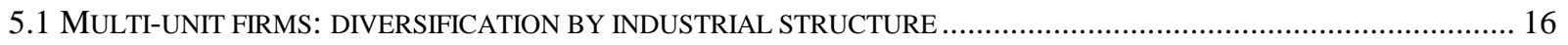

5.2 MULTI-UNIT FIRMS: DIVERSIFICATION BY GEOGRAPHIC STRUCTURE ........................................................... 19

5.3 BROAD-SPECTRUM AND NARROW-SPECTRUM DIVERSIFICATION................................................................. 22

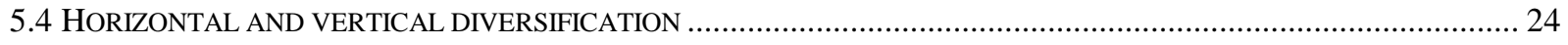

5.5 HORIZONTAL AND VERTICAL SHARES USING DIFFERENT THRESHOLDS ........................................................ 27

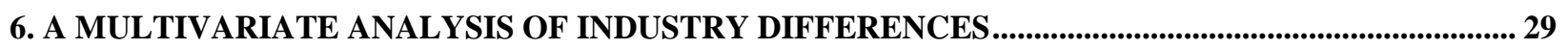

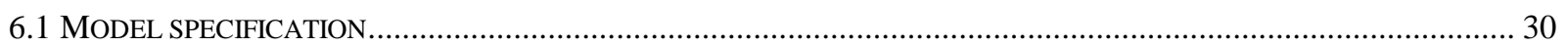

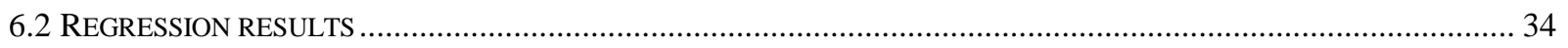

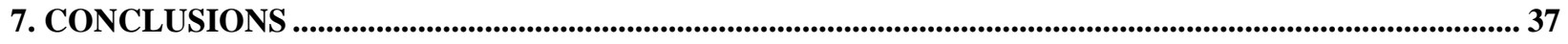

APPENDIX A: DEFINITION OF FIRM......................................................................................................................... 39

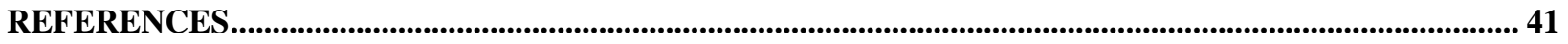

Analytical Studies Branch - Research Paper Series - iii - Statistics Canada No. 11F0019MPE No. 150 


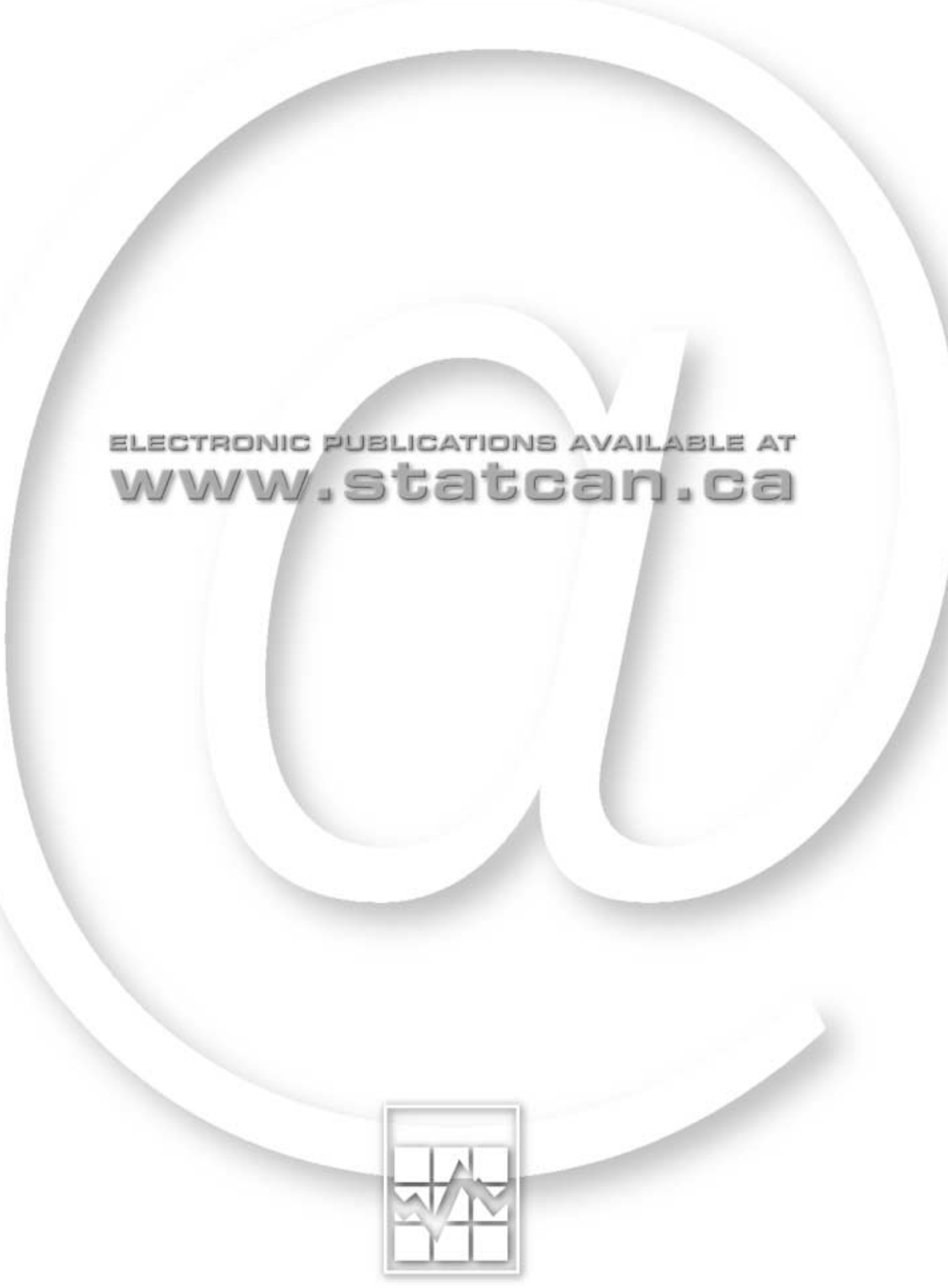




\section{Abstract}

Using a comprehensive micro-database of Canadian firms in conjunction with industry-level data on commodity flows, we develop a profile of corporate diversification within the Canadian economy. Our analysis has two major objectives.

First, we decompose corporate diversification into horizontal and vertical components based on the degree to which industries are linked by inter-industry trade flows. Horizontal and vertical decompositions serve as useful proxies for the strategic factors that underlie diversification strategies. We find that over $80 \%$ of corporate diversification is horizontal in nature - occurring across industries that do not exhibit strong buyer/seller relationships. In the main, this suggests that many firms pursue diversification strategies in order to spread risk and to take advantage of special assets, more so than as a means of improving vertical efficiencies. Seventy-one percent of corporate diversification is also broad-spectrum - representing an expansion of corporate activities across (as opposed to within) 2-digit industry groups.

Our second objective is to ascertain whether diversification patterns are closely associated with certain industry characteristics. Here we consider industry-level factors that are generally posited to affect the level of diversification (e.g., growth, concentration, knowledge-intensity) along with other variables designed to evaluate whether diversified ownership structures are associated with inter-industry commodity flows. Our regression analysis draws on three empirical measures of diversification - first, the amount of total entropy (i.e., diversification) within an industry, second, the average entropy per firm, and last, the percentage of firms within an industry that diversify.

Within our sample of 132 commercial industries, total diversification is positively associated with the intensity of inter-industry trade flows. Hence, the more diversified an industry's buyer/seller linkages with other sectors, the greater the level of corporate diversification that one would expect to find. This provides some evidence that inter-industry trade intensity plays a significant role in explaining overall levels of corporate diversification, where this level is, in turn, determined by (i) the number of diversified firms, and (ii) the average level of diversification within these firms. This said, inter-industry trade flows are not related to the average level of diversification, nor do they help explain the percentage of firms within an industry that become diversified. On these issues, we look to other factors for explanation. Industry concentration and average firm size are both positively associated with the amount of diversification per firm. This is consistent with the 'constrained optimization' view of diversification - large firms in concentrated markets look to diversification strategies as a means of achieving growth, as the potential for further expansion in main product areas is often exhausted.

Sectoral differences in diversification patterns are apparent. A greater percentage of firms in goods-producing industries diversify. There is also some evidence that firms in the goods sector are, on average, more diversified than those in services.

Keywords: diversification, vertical integration 


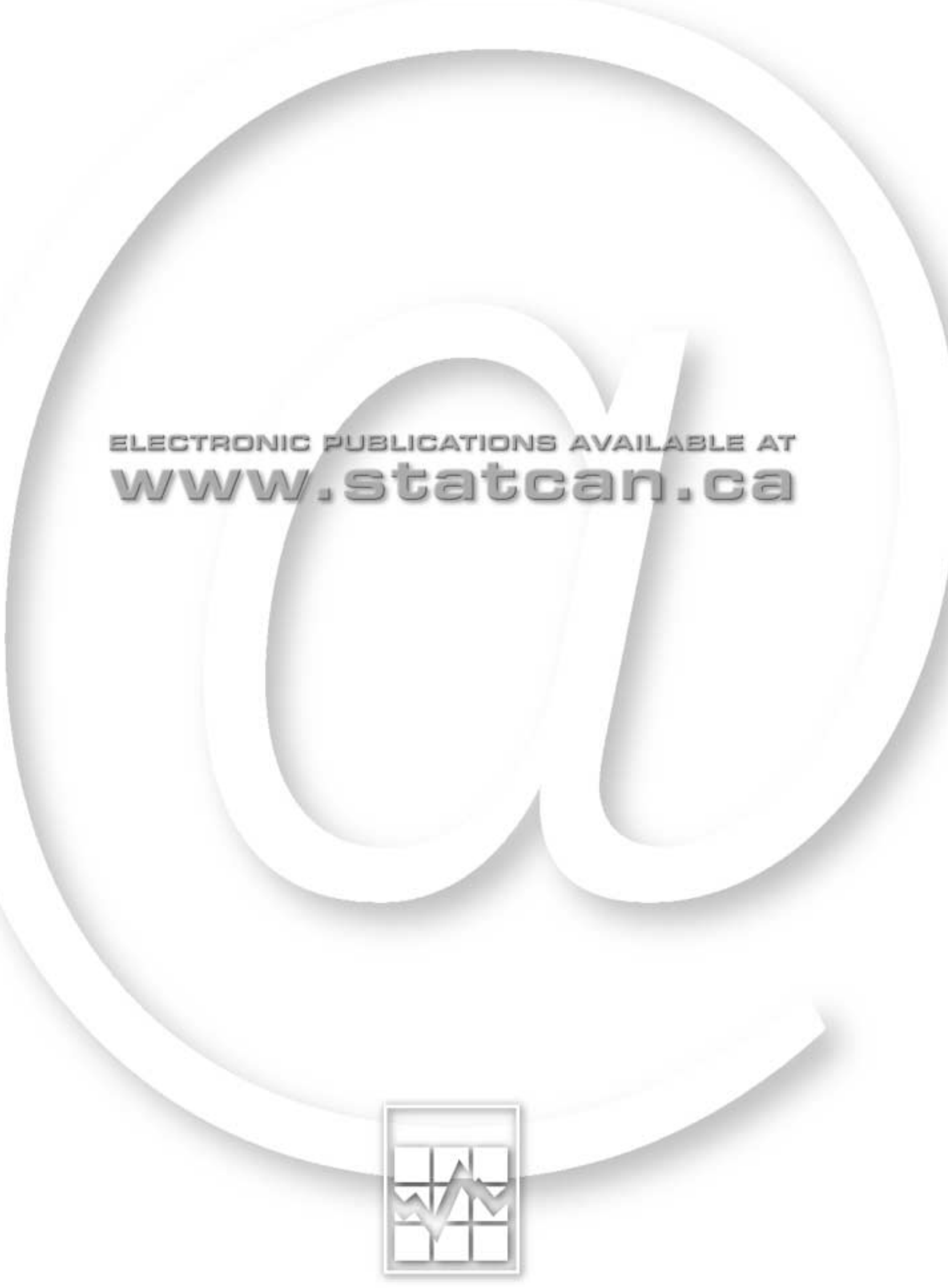




\section{Acknowledgements}

We wish to thank Richard Caves of Harvard University, Donato Iacobucci of the University of Urbino, and Philippe Gagné of Statistics Canada for their helpful comments and suggestions. 


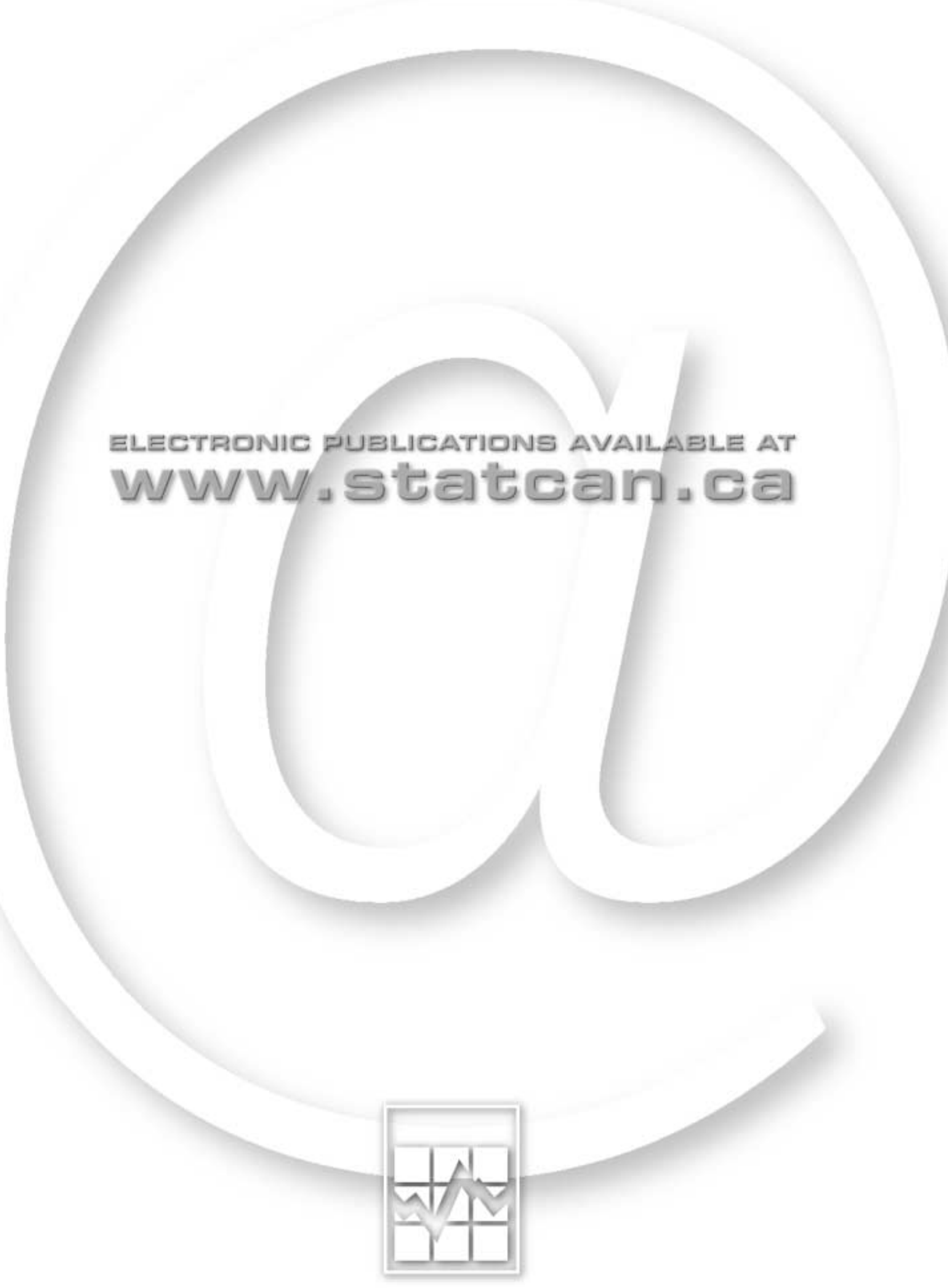




\section{Introduction}

Studies of corporate diversification contribute fundamentally to our understanding of the modern economy. Corporations with complex, multi-unit ${ }^{1}$ operating structures, spanning different product markets and production activities, play a significant role in many economic sectors. These firms seem far removed from the atomistic models of market organization that characterize traditional economic analysis. Yet the diversification strategies pursued by such firms bear directly on issues of competitive strategy, industry growth, resource efficiency, economic power, and market structure.

Firms pursue diversification strategies by establishing production units in different industrial sectors. These production activities may be highly complementary in that they support the firm's core product line. For instance, vertical diversification strategies bring together, within a single operating structure, discrete elements of the production and distribution chain. Firms that establish vertically integrated structures may be able to allocate resources more effectively than via arms-length transactions. ${ }^{2}$

Horizontal diversification occurs when a firm extends its production activities into areas that fall outside of its traditional product line. This allows firms to exploit complementary marketing or technological assets across product lines. It also serves as an important means of risk-spreading, safeguarding corporate revenues from demand shocks in key product markets.

This paper examines the extent of diversification in the Canadian economy. It not only reports on the amount of diversification, but also on the exact form that this diversification takes. It investigates whether, in the main, diversification is a lateral phenomenon across unrelated sectors, or if it represents an attempt to improve efficiencies within a general line of business.

Early empirical research on corporate diversification using large cross-sectional databases has suffered from several limitations. First, operational measures of vertical diversification have not been readily devisable. ${ }^{3}$ As such 'related' production activities tend to be defined as those that fall within 2-digit industries, while 'unrelated' production activities are those that cross 2-digit boundaries. In much of the literature, these serve as proxies for 'narrow-spectrum' and 'broadspectrum' diversification. In our view, these distinctions are conceptually unsatisfying because they reveal very little about whether, on net, diversification is undertaken to bring about efficiency gains via vertical integration or to spread risk and acquire special assets via horizontal extension. Moreover, broad- and narrow-spectrum distinctions also allow for potentially misleading characterizations of 'related' and 'unrelated' industrial activities, as these depend solely on the taxonomical conventions used in standard industrial classification systems. The

\footnotetext{
${ }^{1}$ Many terms can be used to describe the organizational elements of a firm. In this paper, we use the terms unit, establishment, and plant interchangeably.

${ }^{2}$ See Williamson (1975).

${ }^{3}$ Many subsequent studies have addressed this shortcoming by developing measures of vertical diversification. For examples, see MacDonald (1985), Lemelin (1982), Maddigan (1981), Martin (1986) and Davies and Morris (1995). Of this, more later.
} 
principles that give rise to differences in industry classification may not directly accord with any obvious metric of 'relatedness'; for example, it may be the case that activities that fall within a 2digit group are, in fact, less related than those that cross 2-digit industries. ${ }^{4}$ This paper builds on recent efforts to measure vertical diversification - efforts that contribute to our understanding of the strategic factors that underlie diversification strategies. We use horizontal and vertical measures in conjunction with broad- and narrow-spectrum distinctions in order to develop a more comprehensive profile of the diversified population.

A second limitation of earlier research centres on issues of data coverage. Many studies have not been based on comprehensive lists of business populations, which, in turn, raises the spectre of bias. In the absence of comprehensive data sources, some studies have focused on diversified firms in certain sectors, such as manufacturing, at the expense of those in other areas of the economy. Others have drawn from lists of major corporations (e.g., the Fortune 500) which are not representative of the overall corporate population. Both these approaches may give rise to an incomplete view of diversification in the corporate sector. Our objective in the present analysis is to overcome these difficulties by offering an analysis that both distinguishes between horizontal and vertical strategies and covers commercial activity in all sectors of the economy.

Our paper is organized as follows.

In Section 2, we review, in brief, select literature on corporate diversification. Our discussion focuses on the strategic basis for diversification and post-diversification performance.

Data issues are addressed in Section 3. We use Statistics Canada's Business Register - a comprehensive micro-database of Canadian companies - to obtain information on the operating structures of all multi-unit firms. To measure the economic relationships that exist between different industries, we use a second database - based on Statistics Canada's input/output tables - that provides detail on inter-industry commodity flows. Taken together, these data reveal whether the actual patterns of corporate diversification conform to the economic linkages that exist between various sectors of the economy.

In Section 4, we discuss our quantitative measure of diversification. We adopt an entropy-based metric because (i) it allows for convenient summary measures that capture the extent to which a firm's economic activity is distributed among different industrial activities, and (ii) it can be readily decomposed into sub-measures (e.g., broad- versus narrow-spectrum diversification; horizontal versus vertical diversification). We also discuss, in some detail, the utility of these sub-measures.

In Section 5, we examine patterns of corporate diversification within the Canadian economy. First, we present diversification statistics for all major economic sectors based on the employment characteristics of multi-unit firms. The multi-unit population includes both diversified firms (those with production units in different industries) and consolidated firms (those with all units in a single industry). Second, we ask whether a different view of corporate

\footnotetext{
${ }^{4}$ These concerns were raised by Berry (1975). A detailed discussion of these issues is found in Section 4.
} 
diversification emerges when investigating the geographic characteristics of these firms. Third, we return to more conventional measures of corporate diversification by examining broad- and narrow-spectrum entropy based solely on firms that maintain production units in multiple industries. Fourth, we supplement these broad- and narrow-spectrum measures with estimates of horizontal and vertical diversification based on the significance of inter-industry commodity flows. Lastly, we investigate the statistical assumptions that underlie our estimates of vertical diversification.

In Section 6, we use regression analysis to ask whether inter-sectoral differences in diversification are associated with certain industry characteristics. Concentration, growth, average firm size, and knowledge-intensity have all been posited to affect the amount of diversification within an industry. We evaluate these effects, and introduce two additional variables designed to capture changes in diversification arising from differences in the intensity of inter-industry trade flows. These variables are proxies for the establishment of vertical efficiencies - industries having more significant economic linkages with other sectors may also be those with more diversified firms.

We review the central findings of the paper in Section 7.

\section{Perspectives on Corporate Diversification}

\subsection{The strategic basis for diversification}

Firms diversify by establishing (or acquiring) production units that engage in different industrial activities. Diversification is thus an expansion of corporate activity - either into areas that are closely related to a general line of business, or into areas that represent new directions for the firm. Economists have long debated the strategic basis for such decisions. Penrose (1959) and Marris (1964) argue that firms diversify in order to grow. The need for growth may reflect the personal aspirations of managers. Or it may result from strategies designed to maximize shareholder value through the exploitation of firm-specific assets. ${ }^{5}$ Gort (1962) argues that the prospective return on investment is a function of growth and that firms in slow-growing sectors should be expected to diversify into faster-growing sectors.

Many economists see diversification strategies as beneficial. Diversification is one means of extending the boundaries of the firm to solve coordination problems that exist in some markets problems that cause firms to replace arm's-length transactions with internal allocation mechanisms (Williamson, 1975). These difficulties can be particularly severe between firms that are linked in vertical relationships where bilateral monopolies or information asymmetries can lead to market failure. ${ }^{6}$ Strategies that bring together firms that are customers and suppliers may lead to efficiency gains.

\footnotetext{
${ }^{5}$ For an overview of agency theories, in which managers pursue growth strategies in order to maximize their private interests (as opposed to those of the firm), see Montgomery (1994).

${ }^{6}$ See Clarke (1985), chapter 8.
} 
Other strategic factors may motivate firms to diversify. Diversification strategies (and, in particular, mergers) are seen as an efficient response to problems that arise due to the nature of certain assets. This theory proposes that mergers result in synergistic gains when the production process involves 'lumpy' or intangible productive assets that can be used simultaneously in more than one market. To the extent that an asset's intangible quality prevents the firm from fully exploiting its value in a single market, and its exploitation is not possible via an arm's-length sale because of asymmetric information problems, the firm is better off extending itself into new markets. ${ }^{7}$ Examples of such assets involve innovation capabilities or certain marketing capabilities associated with brand images. Diversification strategies are a method of exploiting intangible assets — especially in areas where these assets are more prevalent. ${ }^{8}$

Diversification is also an effective means of managing risk. Vertical or synergistic gains aside, a firm that expands the breadth of its industrial activities will be less vulnerable to demand shocks in single markets. On this view, diversification strategies need not have any direct bearing on issues of vertical efficiency, as these center predominately on improving the firm's position within a primary (and single) line of business. Risk management strategies that involve diversification are more horizontal in nature - firms minimize their exposure to external shocks by establishing or acquiring seemingly disparate holdings, by moving into product markets that they deem lucrative, or potentially so. ${ }^{9}$ Both horizontal and vertical diversification thus represent a form of corporate growth, though the strategic basis for each may differ significantly.

\subsection{Diversification and performance}

Diversification strategies affect the dynamics of competition. Diversified firms may enjoy considerable leverage over competitors. For instance, vertically diversified incumbents may be able to draw on cost advantages in order to price emerging firms out of the market and create barriers to entry. Other competition problems such as predatory pricing, tied selling, and the development of mutual forbearance are also noted as possible consequences of diversification (Clarke, 1985). ${ }^{10}$

Much of the empirical literature on diversification has focused on merger activity. These studies have wrestled with whether merger activities serve to enhance the market for corporate control, thereby increasing efficiency, or whether they satisfy managerial preferences that are not aimed at maximizing shareholder wealth (Caves, 1987; Scherer, 1988). Earlier empirical work has difficulty in identifying the beneficial effects of merger activity, irrespective of whether the merger involved similar acquisition (acquiring firms in the same industry) or diversification

\footnotetext{
${ }^{7}$ See Caves (1975).

${ }^{8}$ Baldwin and Caves (1991) find that the beneficial effects of mergers are greater in science-based industries where intangible assets related to $\mathrm{R} \& \mathrm{D}$ are more prevalent.

${ }^{9}$ The idea that 'unrelated' diversification strategies lead to a reduction in operating risk has been extended by Amit and Livnat (1988). The authors propose a concept of conglomerate diversification that reduces the firm's vulnerability to macroeconomic cycles. Expansion into unrelated product markets is an effective means of reducing operating risk if changes in the business cycle affect the firm's business segments in different ways.

${ }^{10}$ For an overview of the anti-competitive outcomes that can result from diversification (e.g., predatory pricing, mutual forbearance and reciprocal buying), see Montgomery (1994).
} 
(acquiring firms in different industries). Mueller (1987) noted that most mergers result in a loss in market share. Cowling et al. (1980) found little evidence that UK mergers enhanced productivity. Ravenscraft and Scherer (1987), using US data on line-of-business performance, argue that mergers are generally unsuccessful. However, 'related' mergers (those that focus on a single line of business) were more likely to be successful than 'unrelated' mergers (those that combine different lines of business). Work by Jog and Riding (1988) and Tarasofsky (1991), using Canadian data on mergers of firms listed on the Toronto Stock Exchange, find that about equal numbers of post-merger firms succeed or fail.

Not all Canadian studies find mergers to be ineffective. Financial event studies suggest that takeover announcements have positive effects on stock prices. Shareholders of both target and acquiring firms tend to benefit from mergers (Eckbo, 1986 and 1988). What is more, mergers are accompanied by real efficiency gains. Baldwin (1995) uses census data to examine the performance of plants prior and subsequent to merger and concludes that mergers have a significant effect on either productivity or profitability. ${ }^{11}$

Evidence on the beneficial effects of diversified mergers is less forthcoming. The Royal Commission on Corporate Concentration (1978) finds that unrelated diversification in Canada had, at best, neutral effects on firm profitability. Caves et al. (1980) and Lecraw (1984) find that large firms that were classified as unrelated diversifiers, and that were heavily engaged in merger activity, tended to report lower profits over the period 1960-1975 than did less diversified firms. Baldwin (1995) also finds the clearest evidence of gains from mergers when these involve similar firms; unrelated mergers, in contrast, fare less well.

A second set of studies takes as its focus the performance of industries rather than of merged firms. While these studies account for the effects of diversification on all firms (rather than just on large firms), they initially employed relatively crude measures of diversification - such as the ratio of primary employment to total employment for all firms in an industry, where primary employment refers to the employment of the firm in its main industry. This literature is inconclusive as to whether firms in industries that are dominated by diversified firms have greater profitability. Miller (1969) and Rhoades (1973) find that US manufacturing profitability in the late 1950s and early 1960s is negatively related to the ratio of primary to total employment. However, Rhoades (1974) reports that the relationship does not hold for $1967 .{ }^{12}$

\footnotetext{
${ }^{11}$ Lichtenberg (1992) reports similar findings for the United States using data from the US Census of Manufactures.

${ }^{12}$ In addition to industry profitability, much of the early industrial organization literature on diversification focused on its impact on market structure (e.g.) industry concentration and growth. For a review, see Ramanujam and Varadarajan (1989).
} 
The above studies attempt to find broad patterns that describe the general effects of diversification. Others like Rumelt (1974) also examine diversification, but divide the universe of mergers into finer, more disaggregated categories to examine differences in a firm's success. ${ }^{13}$ Rumelt's research asks whether there are finer groupings of diversified firms that are correlated with substantial differences in performance, and whether certain types of diversification were more effective in some situations than in others. The same strategy was adopted in Caves et al. (1980). Here diversification is seen to depend on certain industry and firm characteristics. The work of Rumelt and Caves et al. suggests that the impact of diversification strategies depends, more often than not, on firm-specific factors rather than on characteristics common to all firms in the industry.

\section{Data Issues}

Despite interest in the effects of diversification, few studies address its magnitude - primarily because of difficulties in obtaining comprehensive data on the population of diversified businesses. Gort (1962) draws a sample of 721 enterprises from 1954 US Census records that consists of all multi-establishment companies with over 2500 employees, but he focuses primarily on a sample of 111 of these businesses. Rumelt (1974) examines the history of about 250 Fortune 500 companies over the period 1949 to 1969 . Berry (1975) focuses on the performance of 460 Fortune 500 companies during the early 1960s. In each of these cases, no attempt is made to measure the overall level of diversification in different industries. Caves et al. (1980) use Dun and Bradstreet data on Canadian establishments to study about 2,000 firms in the mid-1970s, but had to rely on only a rough ranking of the importance of plants in different SICs to obtain measures of diversification.

Many of these early studies not only examine a limited sample of firms, but also use relatively simple measures of diversification - such as the number of industries occupied by a company's product line (Federal Trade Commission, 1972). Gort (1962) uses the percentage of economic activity in the firm's primary industry of specialization, as well as the number of industries in which the firm operates. Berry (1975) employs a Herfindahl index of the share of sales in different constituent industries, and then experiments with an entropy measure (Jacquemin and Berry, 1979). Both of the latter measures combine information on the number of industries and on differences in the intensity of the firm's economic activity across these constituent industries.

Rumelt (1974) adopts a richer approach that categorizes types of diversification along strategic lines: single product strategies; diversification strategies with most economic activity in a dominant industry; diversification strategies that focus on related markets; and strategies that

\footnotetext{
${ }^{13}$ Rumelt's pioneering work, which emphasized subjective or categorical measures of diversification, has led many others to examine the relationship between diversification and performance. For discussion, see again Ramanujam and Varadarajan (1989).
} 
concentrate on unrelated product markets. He then looks at how differences in performance vary by type. $^{14}$

In this paper, we use a comprehensive Statistics Canada micro-database that contains detailed information on the operating structures of all firms with employees in Canada. This database is used when developing the frame for Statistics Canada's business surveys. Its comprehensiveness allows us to examine, in detail, diversification patterns in all sectors of the economy.

To measure diversification, we adopt an entropy-based metric. We also pursue the notion that there are different types of diversification by decomposing our measure into additive components - in this case, horizontal and vertical components. The latter is defined as diversification into industries that are closely related in the production and distribution chain - either upstream as suppliers or downstream as customers.

We also estimate diversification at different levels of industrial detail. We analyze patterns of broad- and narrow-spectrum diversification (between and within 2-digit industry groups, respectively) and measure the amount of horizontal and vertical diversification that occurs within these broad- and narrow-spectrum divisions.

We begin by discussing the properties of our data below.

\subsection{Identifying multi-unit firms}

A study of diversification requires, in the first instance, micro-data on the operating structures of multi-unit firms. This information can be obtained from Statistics Canada's Business Register - a comprehensive listing of all firms with employees in the Canadian economy. ${ }^{15}$ It is this data source that allows accurate sample frames to be drawn for Statistics Canada's business survey program. While the agency has long had a centralized Business Register, this was traditionally supplemented with specialized lists that were used to support specific survey programs. Beginning in the late 1980s, many of these data sources were integrated into the central Business Register, thereby increasing its coverage of the business population. In support of this strategy, additional resources were devoted to maintaining the database. As a result, the Business Register now offers, in a single location, an extremely comprehensive picture of Canadian businesses. These businesses correspond to either single legal entity firms or consolidations. ${ }^{16}$ The Register provides a detailed summary of legal and operating structures - including detail on the sales,

\footnotetext{
${ }^{14}$ Rumelt's subjective characterization has been the subject of much subsequent analysis, particularly in the strategic management literature. For an analysis that compares Rumelt's method to SIC-based approaches, see Hall and St. John (1994).

${ }^{15}$ The coverage also includes all firms with at least $\$ 30,000$ annual revenue and all incorporated businesses.

${ }^{16}$ The level of diversification can be affected by the level of coverage of multi-legal firms. An investigation of this issue has found that the Business Register is virtually complete in the identification of consolidations and other multi-legal firms (e.g., partnerships, unincorporated joint ventures).
} 
employment and industry of location of each unit belonging to the business. These units are defined basically at the production or establishment level. ${ }^{17}$

\subsection{Identifying economic linkages between industries}

An additional requirement, essential to our objectives here, is that we obtain data that allow us to estimate the significance of economic relationships between industries. Vertical (horizontal) diversification involves the expansion of a firm's operating structure into related (unrelated) sectors. In order to make this distinction, we use data on the importance of inter-industry commodity flows in order to separate industries into related and unrelated groups. ${ }^{18}$

A vertically integrated firm is one whose production activities include some or all of the steps ranging from the acquisition of raw materials to the sale or servicing of finished products. There are two basic forms of vertical diversification: 'upstream' or 'backward' diversification and 'downstream' or 'forward' diversification. In both cases, the firm engages in production activities that are distinct from, though complementary to, the primary business line. In the classical manufacturing example, firms that expand by diversifying 'upstream' or 'backward' produce raw and/or semi-fabricated materials that are then used as inputs in their existing production processes. Similarly, integration 'downstream' or 'forward' can occur when manufacturing firms engage in wholesale and/or retail operations in order to disseminate their products to consumers.

In both cases, the diversified firm is one that engages in, at minimum, two different industrial activities. As discussed in Section 3.1, micro-level data on operating structures from the Business Register can be used to distinguish between diversified and non-diversified businesses by examining a firm's industrial coverage. The more daunting challenge arises when one attempts to distinguish between 'related sectors' (as required for vertical diversification) and 'unrelated sectors' (referred to here as horizontal diversification).

In practice, measuring these inter-industry relationships is far from trivial. In this analysis, we make use of Statistics Canada's input-output (I/O) tables to estimate the flow of goods and services between sectors at various levels of industrial detail. These I/O tables provide the necessary data to estimate the buyer-seller relationships that exist between industries. These buyer-seller relationships are then used to measure the extent to which a firm's operating structure is vertically or horizontally diversified.

\footnotetext{
${ }^{17}$ The Business Register uses the concept of a production entity to describe the operating structure of a business. This is defined as the "smallest distinct combination of dedicated resources (labour and capital) in a process designed to produce a specific set of goods and services." The overwhelming majority of Canadian businesses are organized as single production entities. Multi-unit firms, such as diversified businesses, have more than one production entity.

${ }^{18}$ Lemelin (1982) finds that the probability of a firm in industry $i$ diversifying into industry $j$ is a function of the share of $j$ 's intermediate input purchases from industry $i$. Our analytical framework borrows from Lemelin's earlier work on input flows; we reserve additional discussion for Section 5.
} 
To restrict our analysis to important inter-industry relationships, we chose a minimum sales threshold of $20 \%$ to define significant vertically-related linkages. (We review our selection of a $20 \%$ lower limit in Section 5.5). To illustrate, if industry A purchases $60 \%$ of its inputs from industry B, $30 \%$ from industry $\mathrm{C}$ and $10 \%$ from industry $\mathrm{D}$, only the A-B and A-C linkages represent vertical relationships. Using this industry-level information, we are then able to assess the extent of vertical and horizontal integration within a diversified firm based on the industry mix within its operating structure. If this firm maintains operating units in industries A, B, and D, then the units in A and B are vertically integrated, while the unit in D represents a horizontally integrated unit within its operating structure.

\subsection{Forward and backward linkages based on Input/Output tables}

A more thorough review of our method for establishing inter-industry linkages based on input/output data is provided below. In this exercise, we make the distinction between backward (upstream) linkages and forward (downstream) linkages.

Backward linkages identify the main suppliers of an industry. Consider a simple example. Industries $\mathrm{A}, \mathrm{B}$, and $\mathrm{C}$ comprise the primary goods sector and provide raw inputs to the manufacturing sector. Industries $\mathrm{W}$ and $\mathrm{X}$ comprise the manufacturing sector. Table 3.3.1 reports the percentage of input purchases that manufacturing industries $\mathrm{W}$ and $\mathrm{X}$ make from the various primary goods industries.

Table 3.3.1: Percentage of manufacturing inputs purchased from primary goods sector

\begin{tabular}{l|cc}
\hline & \multicolumn{2}{|c}{ Manufacturing Sector } \\
& Industry W & Industry X \\
\hline $\begin{array}{c}\text { Primary Goods Sector } \\
\text { Industry A }\end{array}$ & $\mathbf{4 0}$ & 18 \\
Industry B & $\mathbf{4 5}$ & 15 \\
Industry C & 15 & $\mathbf{6 7}$ \\
\hline
\end{tabular}

There are three significant backward linkages connecting manufacturing industries to the primary goods sector. Manufacturing industry W maintains two of these, with linkages to primary goods industries $\mathrm{A}$ and $\mathrm{B}$. There is no significant backward linkage connecting industry W with industry $\mathrm{C}$ because the former purchases less than $20 \%$ of its inputs from industry $\mathrm{C}$. Manufacturing industry $\mathrm{X}$, however, is connected to industry $\mathrm{C}$ via a significant backward linkage, as the latter supplies industry $\mathrm{X}$ with $67 \%$ of its input requirements.

We also look through these 'first-order' linkages (as defined in an input/output table) to examine whether 'second-order' linkages are large enough to establish vertical relationships. In the above example, industry $\mathrm{C}$ does not link directly to $\mathrm{W}$ but it does to $\mathrm{X}$. However, if W's purchases from 
$\mathrm{X}$ are sufficiently large, we can also establish a link between $\mathrm{W}$ and $\mathrm{C}$ through the intermediary industry $\mathrm{X} .{ }^{19}$

Forward linkages identify the users of an industry's products. To illustrate, we now examine, for each of the three primary goods industries, how sales are distributed between the two manufacturing industries.

Table 3.3.2: Percentage of output from primary industries sold to manufacturing sector

\begin{tabular}{l|cc}
\hline & \multicolumn{2}{|c}{ Manufacturing Sector } \\
Industry W & Industry X \\
\hline $\begin{array}{c}\text { Primary Goods Sector } \\
\text { Industry A }\end{array}$ & $\mathbf{8 1}$ & 19 \\
Industry B & 15 & $\mathbf{8 5}$ \\
Industry C & $\mathbf{5 0}$ & $\mathbf{5 0}$ \\
\hline
\end{tabular}

In this simple economy, there are four significant forward linkages connecting industries in the primary goods sector to those in manufacturing (Table 3.3.2). Industry A maintains forward linkages with manufacturing industry $\mathrm{W}$, as $81 \%$ of its total output is purchased by this industry. Only $19 \%$ of industry A's output is purchased by manufacturing industry X, which fails to meet the $20 \%$ threshold. In the case of industry B, significant forward linkages are established with industry $\mathrm{X}$ but not with industry W. Finally, goods industry $\mathrm{C}$ maintains linkages with both manufacturing industries $\mathrm{W}$ and $\mathrm{X}$. Once again, linkages are also identified by looking through these 'first-order' relationships in order to take into account any secondary effects (sales through intermediary industries).

Based on the above methodology, we identified 321 significant economic linkages between industries - 148 backward linkages and 173 forward linkages. ${ }^{20}$ Of these 321 linkages, 25 were duplicates, that is, in the case of two industries, A and B, a forward linkage for industry A (as determined by its share of output purchased by B) was also a backward linkage for industry B (as determined by the share of its input purchased from industry A). Excluding this group of 25 leaves us with 296 unduplicated inter-industry relationships that are economically significant. A substantial portion of these relationships, roughly three quarters, involve the manufacturing sector, either as a seller or as a buyer. Of these, virtually half connect manufacturing industries to other manufacturing industries. Primary industries (especially mining) are also major suppliers to the manufacturing sector. The real estate industry is a significant supplier to virtually all industries in terms of non-residential properties and buildings. Construction, government as well

\footnotetext{
${ }^{19}$ Our approach to measuring inter-industry linkages draws on earlier research on economic clusters; see (e.g.) Roelandt et al. (1997). For distinctions between first-order and second-order linkages, see Yotopoulos and Nugent (1973).

${ }^{20}$ The input/output tables that are used to define these linkages employ an alternative method of industry classification, one that is not directly analogous to the SIC (the industry concept that describes the distribution of businesses on the Business Register). Many of these input/output industries represent either 3-digit SIC industries or combinations thereof. The dimensions of our input/output matrix are $167 * 167$.
} 
as accommodation, food and beverage industries are all major purchasers of manufacturing products.

\subsection{Reconciling industry linkages with operating structure}

Our objective in identifying important inter-industry relationships is to use this information to measure the extent of horizontal and vertical diversification within multi-unit firms. Our convention for doing so is as follows:

If a multi-unit firm has, within its operating structure, establishments in separate industries that are connected via a forward or backward linkage, then these establishments are said to be vertically diversified. If a multi-unit firm has, within its operating structure, establishments in separate industries that are not connected via a forward or backward linkage, then these establishments are said to be horizontally diversified.

Using information on the flow of goods and services between industries thus allows us to make important distinctions concerning the type of diversification evident in individual firms. An establishment mix that reflects important buyer-seller relationships is an indicator of vertical diversification, whereas the absence of such relationships is an indicator of horizontal diversification.

\section{Concepts \& Measures}

\subsection{Estimating diversification within a firm}

Diversification within a multi-unit firm can be quantified in several ways. Some measures focus simply on the number of individual industries in which the firm maintains operating units. Other measures quantify the relative importance of economic activity in the various operating units by focusing on the distribution of some characteristic, such as employment or output, across these units. In what follows, we use an example of the latter metric - an entropy measure of diversification that takes into account the industry mix of operating units as well as the distribution of employment across these units (Berry, 1975). Our measure considers how concentrated a firm's employment is - whether it exists entirely within one industry, or whether it is spread across several industries. More importantly, our index tells us how equally the firm's employment is spread across the industries in which it operates. This index takes the general form:

$$
E(s)=\sum_{i=1}^{N} s_{i} \log \left(1 / s_{i}\right)
$$

where

$\mathrm{s}_{\mathrm{i}}$ equals the share of total firm employment in operating unit $\mathrm{i}$. 
This index takes a value of zero when employment is concentrated entirely within a single industry. At the other extreme, if the firm's employment is spread evenly across K industries, the firm's entropy is maximized at $\mathrm{E}(\mathrm{s})=\log (\mathrm{K})$.

The entropy measure is advantageous in that it can be used to examine the contribution that different forms of diversification make to total entropy. Consider a firm that has operating units in $G$ industry groups. The employment share for set $S_{g}$ is then

$$
S_{g}=\sum_{i \in S_{g}} s_{i} \quad g=1, \ldots, G .
$$

It is possible to decompose the firm's total entropy (its measure of diversification) into two components - the entropy that exists between or across industry groups and the entropy that exists within industry groups. In many studies, these provide basic measures of 'broad-spectrum' and 'narrow-spectrum' diversification, and take the form:

$$
E(s)=E_{b}(s)+\sum_{g=1}^{G} S_{g} E_{g}(s)
$$

where

$$
\begin{aligned}
& E_{b}(s)=\sum_{g=1}^{G} S_{g} \log \left(1 / S_{g}\right) \text { is the entropy between industry groups, and } \\
& E_{g}(s)=\sum_{i \in S_{g}}\left(s_{i} / S_{g}\right) \log \left(S_{g} / s_{i}\right) \text { is the entropy within a group. }{ }^{21}
\end{aligned}
$$

Thus total entropy depends both on the distribution of firm employment across separate industry groups and, more narrowly, on the distribution of firm employment among different industries within an industry group.

These entropy measures can be used to quantify the nature of diversification within a firm. To illustrate, consider a firm that maintains four operating units, three in manufacturing and one in construction. The three manufacturing units are located in separate sub-industries - primary metal, fabricated metal and electronic products. Assume that total employment in the firm is 100, distributed equally between the four operating units. The entropy within the firm can be summarized as follows:

Table 4.1.1: Entropy statistics for a hypothetical firm with a diversified operating structure

\begin{tabular}{lccc}
\hline \multicolumn{1}{c}{ Industrial Structure } & Employment & $\begin{array}{c}\text { Entropy between industry } \\
\text { groups }\end{array}$ & $\begin{array}{c}\text { Entropy within industry } \\
\text { groups }\end{array}$ \\
\hline $\begin{array}{l}\text { Manufacturing (A) } \\
(\mathrm{a} 1=25, \text { a2=25, a3=25) }\end{array}$ & 75 & 0.22 & 0.82 \\
Construction (B) & 25 & 0.35 & 0.00 \\
\hline Entropy (value) & & 0.82 \\
Entropy (share as \%) & 0.56 & 59.4 \\
\hline a1=primary metal plant, a2=fabricated metal plant, a3=electronic products plant
\end{tabular}

\footnotetext{
${ }^{21}$ See Jacquemin and Berry (1979: 359-369) and Clarke and Davies (1983).
} 
In this example, within-group entropy (equation 5) has a value of 0.82 - corresponding to $59.4 \%$ of the entropy, or diversification, within the firm - while between-group entropy (equation 4) has a value of 0.56 , representing $40.6 \%$ of total diversification. This indicates that the firm's employment profile is more diversified within its manufacturing units than between its manufacturing and construction operations.

To see how the entropy of the firm depends on its employment characteristics, consider what occurs if total employment is reallocated within our stylized firm (Table 4.1.2). In case (1), the firm employs 60 workers within its three manufacturing operations: 10 in its primary metal plant, 20 in its fabricated metal plant, and 30 in its electronic products plant. The remaining 40 workers are employed in its construction unit. In case (2), the plant employs 90 workers in its manufacturing operations: 40 in primary metal, 30 in fabricated metal, and 20 in electronic products. The remaining 10 workers are employed in construction. The entropy characteristics of these firms are outlined in Table 4.1.2.

Table 4.1.2: Entropy comparisons for a hypothetical firm under different employment allocations

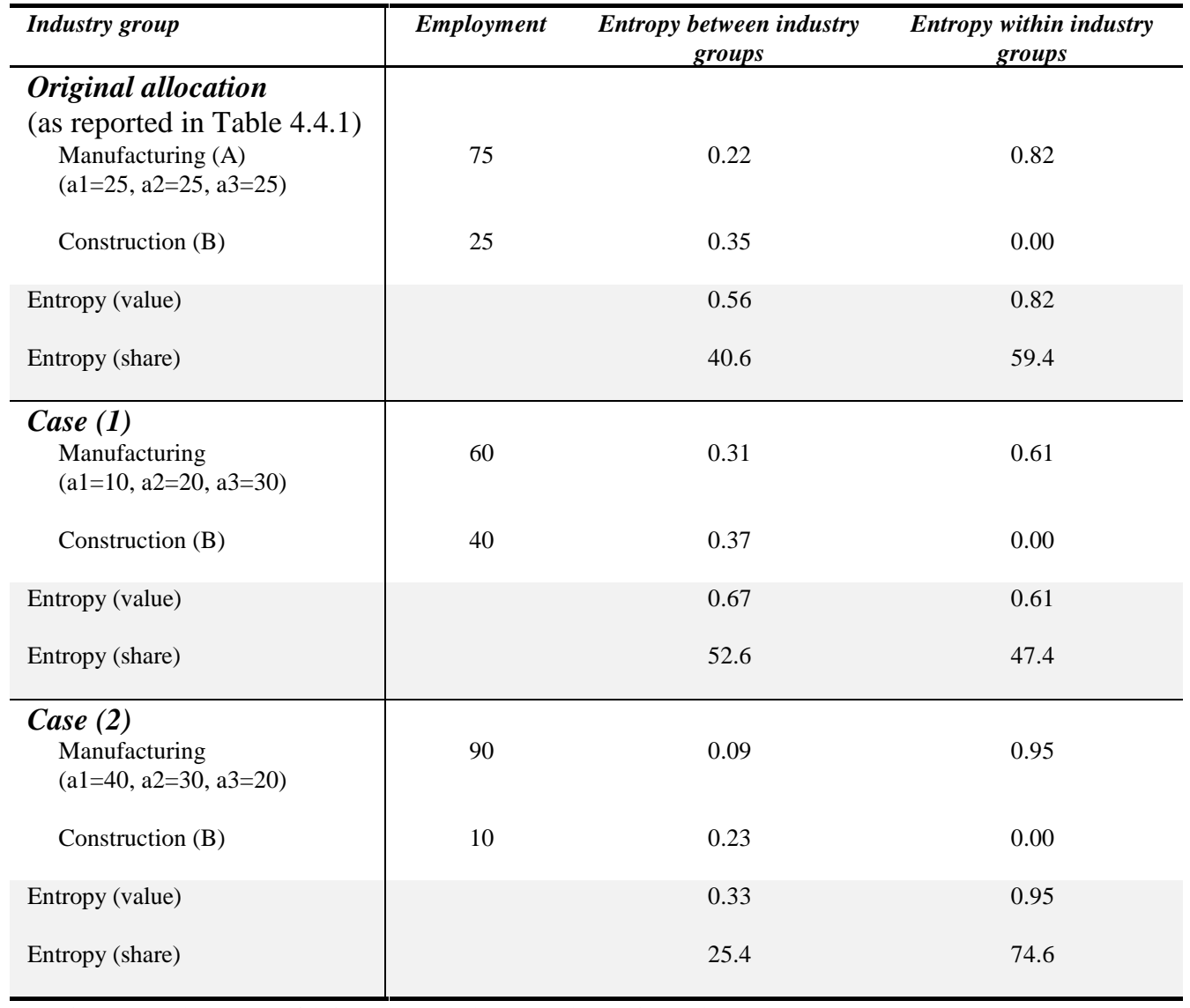

a1=primary metal plant, $\mathrm{a} 2=$ fabricated metal plant, $\mathrm{a} 3=$ electronic products plant 
In case (1), the contribution of between-group entropy to total diversification has increased to $52.6 \%$ because the new employment allocation between manufacturing and construction is more equal than the original allocation (60 and 40 compared to 75 and 25). Accordingly, the entropy that occurs within manufacturing units now represents only $47.4 \%$ of the total. In case (2), the contribution of between-group entropy to total diversification is substantially smaller than in the original allocation (25.4\%) because the vast majority of workers (90 of 100) are employed in manufacturing. The share of entropy within manufacturing is now $74.6 \%$.

Comparisons of the sort outlined above are complicated by the fact that different employment allocations within the firm usually give rise to different levels of total entropy. For example, total entropy based on the original allocation of 25 workers per manufacturing plant was greater $(0.56+0.82=1.38)$ than total entropy in either cases (1) or (2) (both with a value of 1.28). In general, however, for any set of units within the firm - either across or within industry groups - a less equal distribution of employment will give rise to less entropy as more consolidation within certain units implies less diversification. Conversely, more balanced allocations of employment across a set of units will give rise to higher entropy, that is, more diversification.

In this study, we also use a variant of the entropy index that transforms the measure by taking its antilog, which is referred to as the numbers equivalent entropy. This metric takes a value between one and K: it equals one when $100 \%$ of a firm's employment is in one industry and it equals $\mathrm{K}$ when a firm's employment is spread equally across $\mathrm{K}$ industries. Other situations that fall in between are characterized by a numbers equivalent that represents the number of industries over which a firm's employment would need to be equally spread in order to have the same value as the diversity measure. For example, assume that a firm has operating units in 15 industries. Further assume that $75 \%$ of the firm's employment is equally distributed among five of these industries; $20 \%$ of the firm's employment is equally distributed among a second group of five industries; and the remaining 5\% of employment is equally spread across the remaining five industries. This firm is not as diversified as one with employment evenly divided among 15 industries. It is more diversified, however, than one with employment evenly spread across five industries, because its employment is spread evenly across five industries and it has employment in 10 more industries. The weighting scheme embodied in the formula places this firm between the two more extreme cases. According to the entropy formula, this firm has a numbers equivalent entropy of 7.3, which means that the firm is about as diversified as one with employment evenly spread across seven industries.

\subsection{Competing metrics: an overview}

Statistical measures of corporate diversification, such as the entropy metrics discussed above, are a useful means of characterizing the distribution of employment across a firm's range of industrial activities. The above examples focus on 'between 2-digit' and 'within 2-digit' entropy, which, in much of the literature, serve as basic proxies for 'broad-spectrum' and 'narrowspectrum' diversification. ${ }^{22}$

\footnotetext{
${ }^{22}$ A useful discussion of 'relatedness' based on SIC classifications is found in Hall and St. John (1994).
} 
Many see these distinctions as illuminating because of what they (purportedly) reveal about a firm's strategic orientation. Proponents of this view contend that firms that opt for narrow spectrum diversification strategies expand into industries that have similar product characteristics, and hence focus on markets closely related to the primary business line; this may occur because they see a greater potential for future profits in industries that are, in effect, more 'familiar'. These businesses may view entry into dissimilar industries (those with dissimilar product characteristics) as riskier, given that these new product areas constitute less familiar terrain. Hence, firms that opt for narrow spectrum diversification may view their likelihood of success in similar industries to be higher; however, by consolidating their growth opportunities within similar industries, such firms are more vulnerable to cyclical downturns in product cycles that affect narrow groups of industries in the same way. Firms that prefer broad-spectrum strategies may view expansion into industries with diverse product and process characteristics as a means of mitigating demand shocks.

While such interpretations seem sensible, they may be inaccurate. Broad- and narrow-spectrum distinctions attempt to draw a strong correlation between a firm's strategic orientation (its reasons for diversifying) and the industry mix of its establishments (the location of its operating units within a standard industrial classification). As Berry (1975) notes, there are several major difficulties with this approach.

First, it is not immediately apparent that industries that cross 2-digit lines are always more distinct than those located within a two-digit group, simply by virtue of this classification. In fact, some industries within a 2-digit group may actually prove to be more, not less, distinct. Berry offers the example of two manufacturing industries, involved, respectively, in the manufacture of mattresses and wood television cabinets, each of which is classified within a common 2-digit manufacturing group. In practice, however, these represent very different manufacturing activities, to the extent that it becomes difficult to envisage these, in any meaningful sense, as complementary activities within a primary business line. Berry then introduces a third industry that falls outside of this 2-digit group, one involved in the manufacture of plastic television cabinets. The manufacture of plastic television cabinets and wood television cabinets may, in practice, be closely related, whereas the manufacture of mattresses represents the more distinct activity. Hence, the notion that diversification within a 2-digit industry necessarily represents expansion into related or 'familiar' markets breaks down.

In developing this theme, Berry (1975) then draws on the concept of vertical efficiency. It may be the case that broad-spectrum patterns are a more meaningful measure of 'closer' or 'related' industries if these bring together elements of the production and distribution chain. Industries within a 2-digit group may have far less in common in the sense that each represents a different line of business, and that production activities in one (within-group) industry have no direct efficiency effects on production activities in the other (within-group) industry. The utility of these distinctions depends on the factors that are used to group activities into Standard Industrial Classification industries. They may be either demand or supply related. Indeed, they are probably a combination of the two (Abbott and Andrews, 1990). 
All of this is to stress that a profile of corporate diversification based exclusively on broad- and narrow-spectrum patterns - which, in turn, derive solely from Standard Industrial Classification groupings - could be of limited utility. This is not to say that broad- and narrow-spectrum metrics are not useful. In the most basic sense, they reveal how heterogeneous (or homogeneous) a firm's industrial activities are by focusing on differences in product and process characteristics. But they need to be complemented by additional information. For this, we turn to vertical and horizontal measures - which distinguish whether a firm's operating structure brings together units with (or without) significant economic linkages.

In what follows, we use entropy statistics to quantify the level of diversification within Canadian industries, while drawing attention to the various elements of diversified, or entropic, firms: multi-unit operating structures, broad- and narrow-spectrum components, and horizontal and vertical elements. We also examine an alternative concept of diversification - one that focuses on geographic, as opposed to industrial, entropy.

\section{Patterns of Corporate Diversification in Canada}

\subsection{Multi-unit firms: diversification by industrial structure}

Industrial diversification is a phenomenon present only in multi-unit firms. While a diversified firm must have more than a single unit within its operating structure, simply possessing two or more units does not ensure that the firm is diversified. Many multi-unit firms consolidate all of their operating units within a single 4-digit industry - such firms are not industrially diversified. Others, by establishing units in more than one 4-digit industry, are industrially diversified. ${ }^{23}$

It is nonetheless useful to begin our empirical analysis by focusing on the population of multiunit firms, irrespective of whether these businesses maintain consolidated or diversified operating structures. Table 5.1.1 highlights the significance of multi-unit firms within the economy. Slightly more than 13,400 firms have multiple-units within their operating structures. While this group represents less than one percent of the overall firm population, multi-unit firms contribute substantially to total employment and business income. Roughly one-third of the workforce is employed by multi-unit firms. These businesses account for over one-half of total business revenue.

\footnotetext{
${ }^{23}$ We recognize that single-unit firms (which we identify here as non-diversified) may, of course, have multiple activities - activities that, in principle, could fall into different industrial categories. One limitation of our database is that all individual establishments within the firm are classified to a single 4-digit industry - one that corresponds to that unit's dominant industrial activity. For this reason, we are unable to measure industrial diversification within single-unit firms, as this can only be observed in firms with multi-unit operating structures. For an approach using commodity data at the plant level that overcomes this limitation, see Baldwin, Beckstead and Caves (2000).
} 
Table 5.1.1: Business population, $3^{\text {rd }}$ quarter 1998

\begin{tabular}{lccc}
\hline & Multi-unit firms & All firms & $\begin{array}{c}\text { \% accounted for by } \\
\text { multi-unit firms }\end{array}$ \\
\hline Number of businesses & 13,421 & $1,701,821$ & 0.79 \\
Revenue (\$billions) & 1,254 & 2,265 & 55.4 \\
Employment (millions) & 4.96 & 14.53 & 34.1 \\
\hline
\end{tabular}

The proportion of multi-unit firms within an industry will, in part, determine its overall level of diversification. Other things equal, the more multi-unit firms within an industry, the more diversification occurs. $^{24}$ The distribution of multi-unit firms across industry divisions is presented in Table 5.1.2. To evaluate whether some industries are more or less diversified than others, we examine the average numbers equivalent entropy per multi-unit firm. ${ }^{25}$ These values are based on both consolidated and diversified multi-unit firms.

The average numbers equivalent entropy for all multi-unit firms is 1.36 . This means that the average level of diversification within a multi-unit firm is the same as if this firm had its employment evenly spread across 1.36 4-digit industries. We examine inter-industry differences by focusing on three distinct clusters: goods-producing industries, market services, and nonmarket services. ${ }^{26}$

Multi-unit firms in goods-producing industries - ranging from agriculture to construction - are generally more diversified than their counterparts in services. While only $21 \%$ of multi-unit firms are found in the goods sector, they generate $25 \%$ of the numbers equivalent entropy. On balance, their average numbers equivalent entropy per firm stands at 1.56. Multi-unit firms in the logging and forestry industry tend to be the most diversified (1.79), followed by manufacturing (1.64). Firms involved in mining and agriculture tend to be the least diversified (1.37).

Multi-unit firms that provide non-market services also have above-average entropy. ${ }^{27}$ That said, many of these firms do not operate based on market principles. As a consequence, their organizational and employment characteristics may depend largely upon social and political

\footnotetext{
${ }^{24}$ When we measure diversification using numbers equivalent entropy, the level of diversification varies positively with both the number of diversified firms in the industry and the level of diversification within these firms.

${ }^{25}$ Firms are classified to individual industries on the basis of their dominant industrial activity (that is, on the basis of the dominant activity within their establishment mix).

${ }^{26}$ In this analysis, we refer to the 6 industry divisions ranging from agriculture to construction as the goodsproducing sector. Our convention differs slightly from the 1980 Standard Industrial Classification in which the 'other utilities' component of the communications and other utilities industry is also classified to the goods sector. For ease of exposition, we treat 'other utilities' as a service, in order to draw simple distinctions between industry divisions. This simplification is sensible - the majority of multi-unit firms classified to communications and other utilities are in communications, and are thus classified to services. The non-market services sector includes three industry divisions - government, education and health \& social services. The market services sector is made up of the remaining nine industry divisions.

${ }^{27}$ An additional note on the composition of this sector. Its three industry divisions (government, education, health \& social services) include three types of 'firms': (1) government or public entities, (2) government business entities (publicly-held businesses that operate at arm's length from government, such as crown corporations), as well as (3) private firms that operate in these industries.
} 
considerations. This issue aside, the non-market service sector contains $11 \%$ of multi-unit firms and $13 \%$ of total numbers equivalent entropy - with an average numbers equivalent entropy of 1.63. Thus, multi-unit firms in these industries are, on average, slightly more diversified than those in the goods-producing sector. Firms in government services and health and social services exhibit average entropy values near the top of the industrial range (1.73 and 1.63, respectively), while those in education are among the least diversified (1.20).

\section{Table 5.1.2: Distribution of industrial numbers equivalent entropy, by sector}

\begin{tabular}{|c|c|c|c|c|}
\hline Industry Division & $\begin{array}{c}\text { Number of } \\
\text { multi-unit } \\
\text { firms }\end{array}$ & $\begin{array}{c}\text { \% of } \\
\text { employment } \\
\text { accounted } \\
\text { for by multi- } \\
\text { unit firms }\end{array}$ & $\begin{array}{c}\text { Total numbers } \\
\text { equivalent entropy }\end{array}$ & $\begin{array}{c}\text { Average } \\
\text { numbers } \\
\text { equivalent } \\
\text { entropy per } \\
\text { multi-unit } \\
\text { firm } \\
\end{array}$ \\
\hline Agriculture & 109 & 4.8 & 149.40 & 1.37 \\
\hline Fishing & 12 & 9.4 & 16.70 & 1.39 \\
\hline Logging and Forestry & 30 & 17.4 & 53.63 & 1.79 \\
\hline Mining, Quarrying and Oil Wells & 282 & 51.1 & 387.04 & 1.37 \\
\hline Manufacturing & 1,925 & 45.4 & $3,158.84$ & 1.64 \\
\hline Construction & 524 & 9.0 & 743.10 & 1.42 \\
\hline All Goods-Producing Industries & 2,882 & 33.2 & $4,508.72$ & 1.56 \\
\hline Transportation and Storage & 492 & 47.3 & 708.64 & 1.44 \\
\hline Communication and Other Utilities & 190 & 80.7 & 301.61 & 1.59 \\
\hline Wholesale Trade & 2,729 & 38.6 & $3,288.75$ & 1.21 \\
\hline Retail Trade & 2,185 & 37.2 & $2,754.15$ & 1.26 \\
\hline Finance and Insurance & 423 & 48.2 & 522.50 & 1.24 \\
\hline Real Estate Operators and Insurance Agents & 361 & 15.8 & 428.30 & 1.19 \\
\hline Business Services & 994 & 24.1 & $1,096.99$ & 1.10 \\
\hline Accommodation, Food and Beverage Services & 866 & 17.3 & $1,148.03$ & 1.33 \\
\hline Other Services & 833 & 15.0 & $1,103.80$ & 1.33 \\
\hline All Market Services & 9,073 & 33.1 & $11,352.8$ & 1.25 \\
\hline Government Services & 667 & 77.3 & $1,156.46$ & 1.73 \\
\hline Educational Services & 141 & 7.6 & 168.69 & 1.20 \\
\hline Health and Social Services & 658 & 33.4 & $1,070.11$ & 1.63 \\
\hline All Non-Market Services & 1,466 & 37.5 & $2,395.26$ & 1.63 \\
\hline All Industries & 13,421 & 34.1 & $18,256.75$ & 1.36 \\
\hline
\end{tabular}


Firms that provide market-oriented services are, on average, the least diversified. While these services have the largest shares of multi-unit firms and total numbers equivalent entropy (68\% and $62 \%$, respectively), the average numbers equivalent entropy is just 1.25 , significantly less than in goods industries. Thus, while the majority of diversification occurs in services, service firms tend to diversify across fewer industries than do firms in the goods sector. Consequently, the various dimensions that can be used to measure diversification (i.e., numbers of firms versus average levels of diversification) are not perfectly collinear across industries. The most diversified of the market-orientated services include communications and other utilities (1.59) and transportation and storage (1.44). Multi-unit firms in business services have the lowest level of diversification (1.10).

The above data provide a set of first impressions regarding the levels of corporate diversification that prevail across different sectors of the economy. As previously noted, however, these estimates are based strictly on the population of multi-unit firms, without making any allowance for whether or not these firms have consolidated operating structures (i.e., all units in a single industry) or diversified operating structures (i.e., units in two or more industries).

At this stage, we introduce two different perspectives on the operating structure of multi-unit firms. The first of these focuses, as before, on the group of 13,421 multi-unit businesses, and investigates whether firms in certain industries are more geographically diverse than those in other industries. In the second exercise, we focus squarely on our traditional concept of industrial diversification - multi-unit firms that maintain operating units in two or more 4-digit industries.

\subsection{Multi-unit Firms: Diversification by Geographic Structure}

While traditional studies of diversification have focused on a firm's mixture of industrial activities, it is nonetheless useful to consider an alternative metric - based, not on the firm's industrial composition, but rather on the geographic distribution of its operating units. Simply defined, firms that diversify geographically are those that maintain separate operating units in two or more geographic areas. Some of these firms may have consolidated all their operating units within a single industry. Others will have multi-industry operating structures, and thus contain components that are either horizontally or vertically integrated, or some combination thereof. $^{28}$

\footnotetext{
${ }^{28}$ For a more global perspective on geographic patterns, Vachani's (1991) work on developing measures of international geographic diversification is illuminating. Focusing on the behaviour of multinational enterprises, Vachani argues for distinctions between 'homogeneous and heterogeneous' clusters of countries when examining broad and narrow-spectrum diversification patterns, and when investigating the impact of diversification on performance. Kim's (1989) work on developing an entropy-based measure of global diversification, one that decomposes between 'product and international market dimensions', is also informative. An interesting empirical analysis of geographic and product diversification is found in Aw and Batra (1998); the authors examine the effect of firm size on diversification within Taiwanese manufacturing.
} 
In Table 5.2.1, we reproduce the distribution of multi-unit firms from Table 5.1.2 - focusing instead on the extent of geographic diversification within these businesses. Our basic unit of geographic diversification is the municipality. ${ }^{29}$ (This, then, is the conceptual analogue to the 4digit industry measure used to investigate industrial diversification). Prior to any discussion of results, one issue warrants emphasis. Geographic and industrial numbers equivalent entropy statistics are not directly comparable. To see this, consider a population of multi-unit firms within a given industry. A geographic-based numbers equivalent value that is greater than an industry-based numbers equivalent value does not imply, in any meaningful sense, that multi-unit firms within this industry are more diversified geographically than they are industrially. These differences reflect the way in which the respective base units (municipality and 4-digit industry) are scaled. There are 860 different 4-digit industries within the industrial structure; by contrast, there are over 6000 municipalities. As the latter is more narrowly defined, there is a greater likelihood, other things equal, of geographic-based diversification occurring. This would not necessarily be the case if a more restrictive base unit of geography was used, such as province of origin. This said, the purpose of the following exercise is simply to draw distinctions between the level of geographic diversification evident in various industries and sectors.

While goods-producing industries tend to be relatively more diversified across 4-digit industries than those in market services, they are less diversified geographically. Multi-unit firms within market services have a geographic numbers equivalent entropy of 2.98, compared to 2.40 for those in goods-producing industries. Conceptually, then, the average multi-unit firm in market services is about as diversified as one that spreads its total employment evenly across three separate municipalities. Firms in finance and insurance (3.87), retail trade (3.76), and communications (3.53) are among the most geographically diversified. Among goods-producing industries, manufacturers are, on average, more diversified (2.59) than other multi-unit firms, and contribute substantially to the sector's average. Firms in non-market services, particularly those in government services, are less diversified along geographic lines.

The above results suggest that multi-unit firms in the goods sector place more weight on diversification strategies that span industrial activities, whereas those in market-orientated services give more emphasis to geographic expansion. These differences in relative emphasis are sensible. The production of a good differs markedly from the provision of a service. The former often involves a 'classical' input-output structure in which raw materials or intermediate inputs are transformed into final products. A priori, one would expect goods industries to place more emphasis on growth strategies that bring together various elements of the production and distribution chain. While this encourages industrial diversification, other elements of the production process may discourage geographic expansion. Consider a vertically integrated manufacturing firm that maintains two establishments: one to oversee its logging activities and the other for processing pulp and paper.

\footnotetext{
${ }^{29}$ The geographical entropy measures were based on the 1991 Standard Geographical Classification (SGC) for each establishment. Like the SIC, the SGC is hierarchical in nature, ranging from the one-digit region code and two-digit province code down to the 7-digit Census sub-division code (often referred to as the municipality).
} 
Table 5.2.1: Distribution of geographic numbers equivalent entropy, by sector

\begin{tabular}{|c|c|c|c|c|}
\hline Industry Division & $\begin{array}{c}\text { Number of } \\
\text { multi-unit } \\
\quad \text { firms }\end{array}$ & $\begin{array}{c}\text { \% of } \\
\text { employment } \\
\text { accounted for } \\
\text { by multi-unit } \\
\text { firms } \\
\end{array}$ & $\begin{array}{l}\text { Total numbers } \\
\text { equivalent entropy } \\
\text { (geographic) }\end{array}$ & $\begin{array}{c}\text { Average numbers } \\
\text { equivalent entropy } \\
\text { per multi-unit } \\
\text { firm } \\
\text { (geographic) }\end{array}$ \\
\hline Agriculture & 109 & 4.8 & 190.37 & 1.75 \\
\hline Fishing & 12 & 9.4 & 26.31 & 2.19 \\
\hline Logging and Forestry & 30 & 17.4 & 45.47 & 1.52 \\
\hline Mining, Quarrying and Oil Wells & 282 & 51.1 & 649.02 & 2.30 \\
\hline Manufacturing & 1,925 & 45.4 & $4,988.81$ & 2.59 \\
\hline Construction & 524 & 9.0 & $1,020.95$ & 1.95 \\
\hline All Goods-Producing Industries & 2,882 & 33.2 & $6,920.93$ & 2.40 \\
\hline Transportation and Storage & 492 & 47.3 & $1,345.84$ & 2.74 \\
\hline Communication and Other Utilities & 190 & 80.7 & 671.24 & 3.53 \\
\hline Wholesale Trade & 2,729 & 38.6 & $7,299.74$ & 2.67 \\
\hline Retail Trade & 2,185 & 37.2 & $8,210.02$ & 3.76 \\
\hline Finance and Insurance & 423 & 48.2 & $1,635.7$ & 3.87 \\
\hline Real Estate Operators and Insurance Agents & 361 & 15.8 & $1,237.76$ & 3.43 \\
\hline Business Services & 994 & 24.1 & $2,481.76$ & 2.50 \\
\hline Accommodation, Food and Beverage Services & 866 & 17.3 & $2,054.28$ & 2.37 \\
\hline Other Services & 833 & 15.0 & $2,089.73$ & 2.51 \\
\hline All Market Services & 9,073 & 33.1 & $27,026.07$ & 2.98 \\
\hline Government Services & 667 & 77.3 & 856 & 1.28 \\
\hline Educational Services & 141 & 7.6 & 342.11 & 2.43 \\
\hline Health and Social Services & 658 & 33.4 & $1,653.45$ & 2.51 \\
\hline All Non-Market Services & 1,466 & 37.5 & $2,851.56$ & 1.95 \\
\hline All Industries & 13,421 & 34.1 & $36,798.56$ & 2.74 \\
\hline
\end{tabular}

A cost-minimizing multi-plant firm must trade production costs off against transportation costs. Where scale economies are important, the production savings that arise from centralizing multiplant activities within a local area tend, at the margin, to outweigh the increase in transportation costs associated with this strategy. The scale economies associated with geographic concentration are important in goods-producing industries - which then act to discourage geographic diversification.

Firms that provide services often have a production process that is less vertical in nature. Owing to their less tangible or 'physical' quality, services are not transformed from raw or intermediate inputs in the same manner that goods are. Accordingly, there is less of a focus on 'discrete' 
elements of the vertical production and distribution chain, and hence, less of a need to develop distinct operating units within that chain. This may encourage geographical diversification, as service firms are able, with greater ease than their goods-producing counterparts, to replicate their industrial activities in different geographic areas without a substantial cost penalty. More importantly, most services involve the delivery of a product to customers who differ by geographic location. Any cost savings associated with the centralization of services may be outweighed by a loss in value to customers.

\subsection{Broad-spectrum and narrow-spectrum diversification}

In Sections 5.1 and 5.2, we examined two basic applications of our entropy-based metric. First, we explored the extent of 4-digit industrial diversification within the multi-unit population and asked whether firms in certain sectors differ in terms of their entropy characteristics. Second, we focused on geographic entropy and asked whether this gave us a similar view of diversification across sectors. It did not. We found that the entropy characteristics of multi-unit firms differ in these two dimensions. Businesses in the goods sector are more likely to diversify their operations into different industries. Those in market services are more likely to diversify their operations into different geographic locations.

Both of the above exercises focus on a particular firm subpopulation - firms with more than one unit in their operating structure. As previously noted, many of these firms consolidate all of their operations within a single industry. Others are comprised of units that span two or more industries. The average entropy statistics reported in Section 5.1 do not make this distinction. They are based on all multi-unit firms, both 'consolidators' and 'diversifiers' ${ }^{30}$ This provides us with a base measure of diversification within multi-unit firms.

In this section, we turn our attention squarely to the subset of multi-unit firms that operate in more than one 4-digit industry. This reduces our sample from 13,421 to 4,889 firms - 36\% of the multi-unit population. These firms are diversified in the 'classical sense.' Retaining the sectoral focus of previous sections, we report in Table 5.3.1 several summary statistics: the average numbers equivalent entropy, the average log (base 10) entropy, and the share of log entropy that occurs because of diversification between 2-digit industries.

We adopt the log measure of diversification principally for ease of exposition. Log entropy does not have the convenient analytical interpretation of the numbers equivalent measure. It does, however, allow entropy to be more readily decomposed into its constituent components. ${ }^{31}$ In the first of our decomposition exercises, we calculate the share of log entropy arising from two sources: entropy across 2-digit industries and by extension entropy within 2-digit industries. As noted in Section 4, these are standard proxies for broad- and narrow-spectrum diversification.

\footnotetext{
${ }^{30}$ An analogous situation holds for the measures of geographic entropy reported in Section 5.2; these statistics are based both on multi-unit firms that establish operating units in separate locations, and those that do not.

${ }^{31}$ Log entropy can be separated into additive components while numbers equivalent entropy can be divided into multiplicative components.
} 
Differences between the goods and services sectors are less apparent when comparisons are based exclusively on firms that maintain operating units in more than one industry. On average, diversified goods-producing firms exhibit about the same level of numbers equivalent entropy (2.06) as do those that provide market services (1.94). The increase in numbers equivalent entropy per firm in market services follows from the fact that only $26.7 \%$ of these multi-unit firms are diversified, compared to $53.1 \%$ of multi-unit firms in the goods sector. Hence, industries such as fishing and wholesale trade, which previously had below average entropy (on a multi-unit basis) now exhibit above average entropy (on a multi-industry basis). Other industries, such as manufacturing and transportation and storage, exhibit above average entropy using both metrics.

Table 5.3.1: Entropy characteristics of diversified firms, by industry and sector

\begin{tabular}{|c|c|c|c|c|c|c|}
\hline Industry Division & $\begin{array}{l}\text { Number of } \\
\text { diversified } \\
\quad \text { firms }\end{array}$ & $\begin{array}{c}\text { Percentage of } \\
\text { multi-unit } \\
\text { firms that are } \\
\text { diversified } \\
\end{array}$ & $\begin{array}{c}\text { Share of } \\
\text { multi-unit } \\
\text { employment } \\
(\%)\end{array}$ & $\begin{array}{c}\text { Average } \\
\text { numbers } \\
\text { equivalent } \\
\text { entropy } \\
\end{array}$ & $\begin{array}{c}\text { Average } \\
\text { log } \\
\text { entropy }\end{array}$ & $\begin{array}{c}\text { Share of } \\
\text { entropy } \\
\text { between } 2 \\
\text { digit } \\
\end{array}$ \\
\hline Agriculture & 47 & 43.1 & 36.7 & 1.86 & 0.249 & $73 \%$ \\
\hline Fishing & 4 & 33.3 & 21.1 & 2.12 & 0.298 & $91 \%$ \\
\hline Logging and Forestry & 24 & 80.0 & 15.7 & 1.98 & 0.285 & $99 \%$ \\
\hline Mining, Quarrying and Oil Wells & 117 & 41.5 & 75.0 & 1.90 & 0.238 & $73 \%$ \\
\hline Manufacturing & 1,087 & 56.5 & 86.7 & 2.14 & 0.283 & $77 \%$ \\
\hline Construction & 250 & 47.7 & 59.6 & 1.88 & 0.248 & $84 \%$ \\
\hline All Goods-Producing Industries & 1,529 & 53.1 & 82.3 & 2.06 & 0.273 & $78 \%$ \\
\hline Transportation and Storage & 179 & 36.4 & 77.0 & 2.21 & 0.292 & $73 \%$ \\
\hline Communication and Other Utilities & 100 & 52.6 & 65.2 & 2.12 & 0.265 & $62 \%$ \\
\hline Wholesale Trade & 576 & 21.1 & 45.7 & 1.97 & 0.266 & $83 \%$ \\
\hline Retail Trade & 656 & 30.0 & 79.3 & 1.87 & 0.247 & $75 \%$ \\
\hline Finance and Insurance & 126 & 29.8 & 62.3 & 1.79 & 0.227 & $77 \%$ \\
\hline Real Estate Operators and Insurance Agents & 85 & 23.6 & 55.2 & 1.79 & 0.227 & $85 \%$ \\
\hline Business Services & 119 & 12.0 & 17.0 & 1.87 & 0.243 & $67 \%$ \\
\hline $\begin{array}{l}\text { Accommodation, Food and Beverage } \\
\text { Services }\end{array}$ & 349 & 40.3 & 62.8 & 1.81 & 0.232 & $67 \%$ \\
\hline Other Services & 232 & 27.9 & 66.1 & 2.17 & 0.293 & $71 \%$ \\
\hline All Market Services & 2,422 & 26.7 & 61.6 & 1.94 & 0.256 & $75 \%$ \\
\hline Government Services & 520 & 78.0 & 50.1 & 1.94 & 0.228 & $76 \%$ \\
\hline Educational Services & 34 & 24.1 & 42.7 & 1.81 & 0.208 & $80 \%$ \\
\hline Health and Social Services & 384 & 58.4 & 76.8 & 2.07 & 0.287 & $17 \%$ \\
\hline All Non-Market Services & 938 & 64.0 & 59.9 & 1.99 & 0.251 & $49 \%$ \\
\hline All Industries & $\mathbf{4 , 8 8 9}$ & 36.4 & 66.0 & 1.99 & 0.260 & $71 \%$ \\
\hline
\end{tabular}


The entropy characteristics of diversified firms are qualitatively similar across sectors. The average numbers equivalent entropy is in the neighborhood of 2 for virtually all industries. ${ }^{32}$ Businesses in manufacturing and fishing (goods) and communications, transportation, and other services (market services) are among the most diversified.

Firms in both the goods-producing and market services sectors have the majority of their industrial diversification across 2-digit industries (broad-spectrum). Goods-producing industries are, on average, marginally more diversified along broad-spectrum lines than are market services. Diversified firms in fishing and logging and forestry have over $90 \%$ of their industrial entropy in broad-spectrum patterns. Among market services, wholesale trade and the real estate industries have among the highest broad-spectrum shares. Only diversified firms in health and social services (in the non-market sector) maintain an operating mix that is dominated by narrowspectrum diversification.

\subsection{Horizontal and vertical diversification}

In the previous section, we reported the share of broad-spectrum diversification within multiindustry firms. In our view, conventional broad- and narrow-spectrum distinctions are limiting because they reveal very little about the economic relationships that exist between industries, and consequently, about the strategic role that operating units from diverse industries play within a firm's establishment mix. The principal advantage of our data is that we are able to separate broad- and narrow-spectrum diversification into vertical and horizontal components. Unlike the conventional broad/narrow taxonomy, vertical and horizontal distinctions do have an underlying strategic basis - firms engage in vertical integration as a means of improving cost efficiencies along the production and distribution chain, whereas horizontal strategies are a means of spreading risk, or exploiting complementary assets or scope economies in product lines.

Our methodology uses data on interindustry commodity flows to distinguish between vertical and horizontal diversification. This approach can be found in earlier work by, among others ${ }^{33}$, Lemelin (1982) and MacDonald (1985). Using data from Canadian input/output tables, Lemelin examined inter alia the role that vertical buyer/seller relationships and industrial complementarity' play in conditioning the probability of interindustry diversification (at the level of the firm). MacDonald also used input/output data to construct measures of backward and forward supply linkages across industries.

Our first objective in using industry-level commodity data is to decompose total entropy into horizontal and vertical shares, utilizing the method outlined in Section 3. In our earlier hypothetical example, a minimum sales threshold of $20 \%$ was used to define important vertical linkages between industries. In what follows, we retain this convention, and explore the impact of changes to this threshold in Section 5.5.

\footnotetext{
${ }^{32}$ There are, of course, sharp differences in the both the numbers of diversified firms and total log entropy across sectors.

${ }^{33}$ Other useful applications of input/output data in developing measures of vertical integration are found in Martin (1986) and Maddigan (1981).
} 
The incidence of vertical and horizontal diversification within the multi-industry population is outlined in Table 5.4.1.

Table 5.4.1: Composition of the multi-unit population

\begin{tabular}{lcccc}
\hline Composition of firm & $\begin{array}{c}\text { Number } \\
\text { of firms }\end{array}$ & $\begin{array}{c}\text { Number of } \\
\text { operating units }\end{array}$ & Total employment & Total revenue (\$B) \\
\hline Diversified firms (multi-industry) & $\mathbf{4 , 8 8 9}$ & $\mathbf{4 9 , 1 5 7}$ & $\mathbf{3 , 2 7 1 , 3 6 4}$ & $\mathbf{8 0 0 . 4}$ \\
$\quad$ Only vertically integrated units & 448 & 6,109 & 332,809 & 103 \\
$\begin{array}{l}\text { Mixture of horizontally and vertically } \\
\text { integrated units }\end{array}$ & 398 & 10,708 & 917,930 & 304.8 \\
$\quad$ Only horizontally integrated units & 4,043 & 32,340 & $2,020,625$ & 392.6 \\
Consolidated firms (single industry) & $\mathbf{8 , 5 3 2}$ & $\mathbf{3 3 , 6 8 5}$ & $\mathbf{1 , 6 8 9 , 9 5 0}$ & $\mathbf{4 5 3 . 7}$ \\
All multi-unit firms & $\mathbf{1 3 , 4 2 1}$ & $\mathbf{8 2 , 8 4 2}$ & $\mathbf{4 , 9 6 1 , 3 1 4}$ & $\mathbf{1 , 2 5 4 . 0}$ \\
\hline
\end{tabular}

Of the 13,421 multi-unit businesses, 8,532 are non-diversified, as they operate units in only a single 4-digit industry. The remaining 4,889 firms - or $36 \%$ of the multi-unit population maintain industrially diversified operating structures. The vast majority of these firms, $83 \%$, are horizontally integrated; that is, they operate business units in industries that are not connected via important forward or backward industry linkages. Nine percent of diversified firms are completely integrated along vertical lines, operating units solely in industries that maintain significant economic relationships. Slightly less, $8 \%$ of diversified firms, exhibit elements of both horizontal and vertical integration within their establishment mix.

The size characteristics of these firms vary with the operating structure. Even though firms that contain only horizontally integrated units greatly outnumber other multi-industry firms, their average size, whether measured in terms of units per firm, employment, or revenue, is relatively small. These firms operate, on average, 8 business units, employ 500 workers and generate $\$ 97$ million in annual revenue. By contrast, firms whose operating structures reflect a mixture of horizontal and vertical diversification are considerably larger, with, on average, 27 business units, 2,306 workers and \$765 million in annual revenue. Firms that contain only vertically integrated units occupy the middle ground, with, on average, 14 operating units, 743 employees and $\$ 230$ million in revenue.

These horizontal and vertical decompositions are illuminating - particularly when crosstabulated with earlier broad- and narrow-spectrum measures. We present the relative incidence of horizontal/vertical and broad/narrow spectrum diversification in Table 5.4.2.

Table 5.4.2: Distribution of total log entropy for multi-industry firms, all industries

\begin{tabular}{lccc}
\hline & $\begin{array}{c}\text { Broad-Spectrum } \\
\text { (Across 2-Digit Industries) }\end{array}$ & $\begin{array}{c}\text { Narrow-Spectrum } \\
\text { (Within 2-Digit Industries) }\end{array}$ & Total \\
\hline Horizontal Diversification & $57.5 \%$ & $25.0 \%$ & $82.5 \%$ \\
Vertical Diversification & $13.5 \%$ & $4.0 \%$ & $17.5 \%$ \\
Total & $71.0 \%$ & $29.0 \%$ & $100.0 \%$ \\
\hline
\end{tabular}


While the majority (71\%) of corporate diversification occurs across 2-digit industries, only about one-fifth of this broad-spectrum component is comprised of ownership patterns that link vertically integrated industries. Accordingly, the lion's share of broad-spectrum diversification represents an expansion of corporate activity into industries that do not exhibit strong interindustry trade flows. Horizontal and vertical shares within the narrow spectrum component reveal a similar pattern. Only $14 \%$ of narrow-spectrum diversification is vertical.

These decompositions are presented at the sectoral level below.

Table 5.4.3: Distribution of total log entropy for multi-industry firms, by sector

\begin{tabular}{lccc}
\hline & $\begin{array}{l}\text { Broad-Spectrum } \\
\text { (Across 2-Digit Industries) }\end{array}$ & $\begin{array}{l}\text { Narrow-Spectrum } \\
\text { (Within 2-Digit Industries) }\end{array}$ & Total \\
\hline Goods-Producing Sector: & $65.6 \%$ & $16.3 \%$ & $81.9 \%$ \\
$\quad$ Horizontal Diversification & $12.5 \%$ & $5.6 \%$ & $18.1 \%$ \\
$\quad$ Vertical Diversification & $78.1 \%$ & $21.9 \%$ & $100.0 \%$ \\
$\quad$ Total & & & $80.5 \%$ \\
Market Services: & $59.9 \%$ & $20.6 \%$ & $19.5 \%$ \\
Horizontal Diversification & $16.0 \%$ & $3.5 \%$ & $100.0 \%$ \\
Vertical Diversification & $75.9 \%$ & $24.1 \%$ & $90.3 \%$ \\
$\quad$ Total & & & $9.7 \%$ \\
Non-Market Services: & $32.5 \%$ & $57.8 \%$ & $100.0 \%$ \\
Horizontal Diversification & $7.4 \%$ & $2.3 \%$ & $60.1 \%$ \\
$\quad$ Vertical Diversification & $39.9 \%$ & & \\
Total & & & \\
\hline
\end{tabular}

Vertical linkages constitute only about one-fifth of all diversification patterns in both the goodsproducing and market services sectors (Table 5.4.3). Broad- and narrow-spectrum shares are also qualitatively similar, with slightly more weight on the former in goods-producing industries. ${ }^{34}$ While one might expect to observe more vertically integrated, broad-spectrum diversification in the goods sector (due to higher levels of differentiation in the production process), our evidence, in the aggregate, does not support such a characterization. The share of vertically integrated broad-spectrum diversification is actually lower in goods industries (13\%) than in market services $(16 \%)$.

Do these sectoral averages belie more subtle industry trends? For instance, is vertically integrated, broad-spectrum diversification more apparent among diversified manufacturers enterprises wherein one might expect to find more 'classical' operating structures that incorporate various elements of the production and distribution chain? While some inter-industry differences are indeed evident - they are not, at first glance, obvious. Only $14 \%$ of total diversification within manufacturing occurs across vertically integrated industries that cross 2digit groups. This suggests that, in the main, manufacturing firms are not pursuing diversification strategies in order to realize vertical efficiency gains. Among goods-producers, the highest shares

\footnotetext{
${ }^{34}$ Pairwise tests of competing proportions indicate that shares values across the goods and services sectors are statistically different. On strictly economic grounds, however, these differences are not substantive.
} 
of vertically integrated broad-spectrum diversification occur within fishing and logging and forestry. Firms in several service industries also score highly, most notably those in finance and insurance and business services.

Taken together, these broad/narrow and horizontal/vertical cross-tabulations are informative because of their inferential power. Our evidence suggests that the majority of corporate diversification - irrespective of whether this occurs between or within 2-digit groups - does in fact occur across 'unrelated sectors' insofar as we do not observe strong inter-industry trading relationships of the sort that would suggest vertically integrated structures. ${ }^{35}$ While 'vertically' and 'horizontally' motivated diversification strategies are conceptually useful, they should not, in practice, be seen as mutually exclusive. The most economically significant diversified firms are those that combine horizontal and vertical strategies within their operating structure (Table 5.4.1). This suggests that within large and complex firms, diversification strategies serve many different objectives.

\subsection{Horizontal and vertical shares using different thresholds}

The horizontal and vertical shares presented in Section 5.4 are based on a $20 \%$ sales threshold. We chose this threshold as, in our view, it represents a sensible lower limit for capturing intensive interindustry trade flows. That said, any threshold value, ours included, is essentially arbitrary and should not be accepted without scrutiny. It may be that a $20 \%$ cut-off is unduly restrictive (that is, too 'high') in that it systematically underestimates the amount of vertical diversification that is actually occurring within multi-industry firms. In what follows, we analyze the characteristics of diversified businesses under alternative thresholds - those designed to capture progressively broader definitions of vertical integration.

This comparative exercise is necessitated by earlier work on interindustry linkages. In his study of U.S. manufacturing, MacDonald (1985) uses a 1\% threshold to distinguish between vertical and horizontal linkages, a value that is much lower than our $20 \%$ cut-off. In what follows, we analyze four different minimum cut-offs $(20 \%, 10 \%, 5 \%$ and $1 \%)$ for capturing vertical relationships (Table 5.5.1). ${ }^{36}$

\footnotetext{
${ }^{35}$ A qualification on our use of the term 'unrelated': Industries that do not maintain significant trade linkages are only 'unrelated' in the sense that diversification strategies that combine these industrial activities (within the firm) are not designed to enhance vertical efficiencies. Horizontal industries may, of course, be 'related' in other ways; for example, they may share technological or marketing symmetries that make their inclusion in diversification strategies advantageous.

${ }^{36}$ Secondary linkages were eliminated when estimating the distribution of entropy under the $5 \%$ and $1 \%$ thresholds. The quantitative impact of these omissions is minor.
} 
Table 5.5.1: Vertical thresholds, minimum values

\begin{tabular}{lcl}
\hline Threshold Value & Number of Linkages* & Description \\
\hline Case 1: $20 \%$ & 230 & $\begin{array}{l}\text { This threshold classifies only 'intensive' interindustry trade } \\
\text { flows as vertical. }\end{array}$ \\
Case 2: $10 \%$ & 543 & $\begin{array}{l}\text { In addition to 'intensive' trade flows, this threshold allows } \\
\text { vertical linkages of a more 'intermediate' nature }(10 \%-20 \%) .\end{array}$ \\
Case 3: $5 \%$ & 1,228 & $\begin{array}{l}\text { More inclusive, this threshold also classifies reasonably } \\
\text { 'weak' trade flows (5\% - 10\%) as vertical. }\end{array}$ \\
Case 4: $1 \%$ & 4,513 & $\begin{array}{l}\text { The most inclusive definition of vertical diversification, this } \\
\text { threshold treats all linkages that are greater than } 1 \% \text { as } \\
\text { vertical. }\end{array}$ \\
\hline
\end{tabular}

* Primary linkages only. Includes duplicate linkages (backward-to-forward and forward-to-backward linkages within same industry pair).

The entropy characteristics of diversified firms based upon the above thresholds are reviewed in Table 5.5.2.

Table 5.5.2: Distribution of total log entropy for multi-industry firms, by threshold value

\begin{tabular}{lccc}
\hline & $\begin{array}{c}\text { Broad-Spectrum } \\
\text { (Across 2-Digit Industries) }\end{array}$ & $\begin{array}{c}\text { Narrow-Spectrum } \\
\text { (Within 2-Digit Industries) }\end{array}$ & Total \\
\hline Case 1: 20\% Threshold & $57.5 \%$ & $25.0 \%$ & $82.5 \%$ \\
Horizontal Diversification & $13.5 \%$ & $4.0 \%$ & $17.5 \%$ \\
Vertical Diversification & $71.0 \%$ & $29.0 \%$ & $100.0 \%$ \\
Total & & & $74.1 \%$ \\
Case 2: 10\% Threshold & $51.0 \%$ & $23.1 \%$ & $25.9 \%$ \\
Horizontal Diversification & $20.1 \%$ & $5.9 \%$ & $100.0 \%$ \\
Vertical Diversification & $71.0 \%$ & $29.0 \%$ & $53.5 \%$ \\
Total & & & $46.6 \%$ \\
Case 3: 5\% Threshold & $32.8 \%$ & $20.7 \%$ & $100.0 \%$ \\
Horizontal Diversification & $38.3 \%$ & $8.2 \%$ & $24.0 \%$ \\
Vertical Diversification & $71.1 \%$ & $28.9 \%$ & $76.1 \%$ \\
Total & & & $100.0 \%$ \\
Case 4: 1\% Threshold: & $9.9 \%$ & $14.0 \%$ & $15.1 \%$ \\
$\quad$ Horizontal Diversification & $61.0 \%$ & $29.1 \%$ & \\
Vertical Diversification & $70.9 \%$ & & \\
Total & & & \\
\hline
\end{tabular}

In the first instance, the move from our $20 \%$ threshold to a less restrictive $10 \%$ cut-off has little effect on the distribution of total entropy among diversified firms. A $10 \%$ threshold increases the amount of vertical diversification in the economy by $8.4 \%$, with the lion's share of this increase $(6.6 \%)$ occurring across 2 -digit industries. This too is sensible - operating structures that cross 2digit industries are more likely 'to produce' vertical efficiencies (as these broad spectrum patterns combine discrete elements of the production and distribution chain). These vertical gains aside, roughly three-quarters of total diversification occurs across horizontal or 'unrelated sectors' - in this case, industries with trade flows that do not meet the $10 \%$ threshold. 
If we relax the threshold further to 5\%, the amount of vertical integration across 2-digit industries increases to $38 \%$ of the total. In this less-restrictive framework, over half of all broad-spectrum diversification becomes vertical, occurring across related industries. Interestingly, however, the majority of total diversification in the economy (53\%) remains horizontal in nature. Thus, substituting a $5 \%$ threshold for the original $20 \%$ cut-off does not alter our finding that corporate diversification is more prevalent across unrelated sectors than across related sectors.

The adoption of a $1 \%$ threshold gives rise to a very different view of corporate diversification. Herein, the vast majority of all broad-spectrum diversification occurs across related industries. Even among narrow-spectrum groupings (that is, within 2-digit industries) vertical diversification is slightly more common than horizontal diversification.

The choice of a sales threshold depends, in the final analysis, on one's subjective preference along this weak-to-intensive continuum. In what follows, we focus exclusively on intensive interindustry linkages - those strong trade relationships that satisfy our original $20 \%$ rule. We examine whether the existence of such linkages, coupled with other industry-level characteristics, offers an explanation for observed differences in diversification patterns across sectors.

\section{A Multivariate Analysis of Industry Differences}

In this section, we explore whether diversification patterns are related to specific industry characteristics. We do so recognizing the findings of Rumelt (1974) and Caves et al. (1980) which suggest that diversification, in the main, is more closely related to the idiosyncrasies of individual firms than to the characteristics of industries - since it derives from advantages that are specific to certain firms and not to all firms within an industry. ${ }^{37}$

Nevertheless, earlier studies have found that diversification patterns are associated with certain industry characteristics. Gort (1962) examined whether industry growth, productivity change, cyclical variability, concentration, average firm size, and the ratio of technical personnel to the industry workforce were related to the diversification patterns of firms in his sample. ${ }^{38}$ Firms were more likely to diversify into industries that were either growing, more productive, or that had a high technical personnel ratio. The latter effect was particularly important, suggesting that knowledge-based assets are strongly associated with diversification patterns. Firms with knowledge-based assets tend to enter other industries where the use of these assets is important.

\footnotetext{
${ }^{37}$ On a contrarian note, Pomfret and Shapiro (1980) offer evidence that one idiosyncratic characteristic, firm size, is not strongly related to diversification, at least within their sample of large Canadian corporations. They found 'industry factors (to be) far more important than firm size in determining inter-firm variations in diversification' (p.140).

${ }^{38}$ The analysis was done using the number of product additions as a measure of changing diversification at the 2digit industry level.
} 
On the other hand, firms were more likely to diversify out of industries that were growing slowly or highly concentrated. This reflects a type of constrained optimization - firms that pursue diversification strategies as a means of achieving growth or profitability may be forced to turn to external markets if the potential for growth or profitability in primary markets is diminished.

The relation between diversification patterns and knowledge activity has emerged as a central line of research. Studies by Amey (1964), Gorecki (1975) and Grant (1977) confirm the importance of knowledge-based activity. Like Gort (1962), Gorecki (1975) finds knowledgebased activity to be more important in explaining industry levels of diversification than growth, concentration or marketing intensity. Grant (1977) also finds that diversification occurs into higher growth industries. ${ }^{39}$

Canadian diversification patterns during the mid-1970s were examined at the industry level by Caves et al. (1980). Drawing on a sample of 77 industry groups, the authors found that diversification was associated with growth, profitability, concentration and firm size. Industries that have large firms are also those in which diversification is more widespread. Diversification occurs more in industries with higher concentration, higher profits, lower growth and lower exports - but these effects are only evident when variables are interacted with one another. On their own, these variables have no significant influence, suggesting that the industry characteristics that condition diversification are quite specialized.

In this section, we ask whether various industry-level measures of corporate diversification are closely associated with a set of industry characteristics, such as growth rates, concentration ratios, expenditures on advertising, investments in knowledge intensity, and trade flows. We examine a total of 132 industries in the business sector (goods-producing industries and market services) and a sub-sample of 90 industries in the manufacturing sector.

\subsection{Model specification}

Three different empirical measures of industry diversification are used in our analysis. These are:

$\begin{array}{lll}\text { TOTAL } & = & \text { total log entropy } \\ \text { AVERAGE } & = & \text { average entropy per firm } \\ \text { PERCENT } & = & \text { the percentage of firms that are diversified }\end{array}$

\footnotetext{
${ }^{39}$ Our review here is by no means exhaustive, as many others have investigated the relationship between diversification and industry characteristics. Berry (1975) finds a positive association between diversification and industry growth. Corroborating evidence is found by Lemelin (1982). MacDonald (1984) found that diversification occurs into high-growth, high profit industries, and that diversification also leads to less concentration (i.e., more competition) in highly-concentrated industries. Berry found that diversification leads to less concentration in 'more concentrated' sectors and more concentration in 'less concentrated' sectors; Caves also found evidence of the latter effect (for discussion of these studies, and of concentration more generally, see Montgomery, 1994).
} 
The first dependent variable (TOTAL) is our earlier metric of diversification, expressed in log form and summed over all firms in an industry. ${ }^{40}$ This measure is positive for all diversified firms - those with operating units in two or more industries. It takes a value of zero for all other firms.

Our first dependent variable (TOTAL) combines two effects: (1) the number of diversified firms, and (2) the average level of diversification within these firms. Our second dependent variable (AVERAGE) focuses on average entropy per firm.

The third variable (PERCENT) is a more rudimentary measure of diversification. It is simply the percentage of firms in an industry that diversify into more than one industry. We include this variable in the analysis as an alternative to our more comprehensive entropy-based measures.

Our set of explanatory variables is described in Table 6.1.1.

Table 6.1.1: Explanatory variables used in the regression analysis

\begin{tabular}{ll}
\hline Variable & Description \\
\hline CONC & Growth in real industry GDP over the period 1980-1995 \\
MGMT & Ratio of employment of the 8 largest firms to total industry employment (1998) \\
TWKR & Technical management personnel as a percentage of total employment (1996) \\
ADVT & Technology workers as a percentage of total employment1 (1996) \\
LINK & Ratio of advertising expenditures to total industry sales (1995) \\
INDENT & $\begin{array}{l}\text { Number of forward and backward linkages (using the 20\% threshold) with } \\
\text { other industries (1993) } \\
\text { Sum of forward and backward inter-industry entropy (1993) }\end{array}$ \\
GVGESIZE & Average number of employees per firm (1998) \\
\hline
\end{tabular}

The idea that diversification represents a form of constrained optimization can be found in Marris (1964). According to his 'push-model' of diversification, the relationship between industry growth rates and diversification should be negative. In industries where the potential for expansion is limited, firms are less able to pursue growth-oriented strategies. Managers, who derive clear benefits from growth strategies, are thus forced to look outside the main product line in order to expand the scope of their operations. Hence, the absence of opportunities in the primary business line necessitates diversification. Of course, diversification from slower to faster growing industries may also be a means of switching assets from less profitable to more profitable industries (Gort, 1962).

\footnotetext{
${ }^{40}$ We also experimented with a variable that captures the numbers equivalent, but found much the same results as those reported here.
} 
Recent work has found that growth in industry output is positively correlated with plant creation and horizontal acquisitions (Baldwin, 1995). Higher growth industries experience more entry; lower growth industries, more exit and divestiture. While the former suggests that we should find diversification taking place into faster growing industries, it is not clear that we should expect firms from slower growing industries to always be at the forefront of colonizing profitable sectors.

Our growth variable (GWTH) is the rate of growth in industry real GDP over the fifteen year period from 1980 to 1995. Long-run growth rates were chosen since diversification involves major structural shifts that are likely to occur slowly over time.

Marris' constrained optimization framework also suggests that industry concentration should affect diversification patterns. Large firms operating in concentrated markets may look to diversification strategies as a means of achieving growth, as the potential for further expansion in their main product areas is limited. Smaller firms in concentrated sectors have a different rationale for adopting diversification as a growth strategy - entry into 'secondary markets' is less likely to draw reaction from large rivals (Gort, 1962).

These issues aside, there is empirical evidence to support the proposition that market concentration encourages firms to expand the scope of their operations in specific ways. Baldwin (1995) has shown that acquisition activity and start-ups by continuing firms are more prevalent in concentrated industries than greenfield entry. Concentrated industries experience almost the same amount of market turnover from market share being transferred from declining to growing firms, but here entry and exit is more likely to occur via merger activity.

Our concentration variable (CONC) is the ratio of employment of the 8 largest firms to total industry employment.

Knowledge assets are posited to be correlated with diversification patterns because of the importance of specialized assets to the diversification process. Technological innovations generated by research activities create new market opportunities for the firm, which then modifies its operating structure by diversifying. ${ }^{41}$ Because of the importance of knowledge intensity in previous studies, two separate variables are used to capture the role of knowledge assets. These variables are based on two classes of knowledge workers - technology workers and technical managers. The first, (MGMT), is the ratio of technical managers to total employment. The second, (TWKR), is the ratio of knowledge-based personnel to total employment. ${ }^{42}$

\footnotetext{
${ }^{41}$ Alternately, diversified firms, given their greater capacity for creating and coordinating knowledge, are more able to internalize the benefits of research and development than are their non-diversified counterparts, and are thus more likely to engage in research activities (Clarke, 1985).

42 These data come from the 1996 Census. The management category was comprised of legislators and senior management, engineering and science managers, information systems and data processing managers, telecommunication carriers managers and supervisors in manufacturing. These correspond to the 1991 Standard Occupational Classification (SOC91) codes A01, A121, A122, A311 and J0. The technical workers category included professional occupations in natural and applied sciences, technical occupations related to natural and applied sciences, technical and related occupations in health and graphics arts technicians. These correspond to SOC91 codes C0, C1, D2 and F123.
} 
Other specialized assets are generated by advertising expenditures. These may allow firms that develop marketing competencies to diversify their product range with greater ease. These firms may also benefit from the 'accumulation of goodwill' - the notion that market advantages enjoyed in the primary business line (owing, for example, to customer loyalty or brand recognition) will create advantages as the firm diversifies into new markets. To account for this effect, we include a variable (ADVT) defined as the ratio of advertising to total industry sales.

We also include a measure of average firm size (AVGESIZE) to standardize for an industry characteristic that has previously been found to influence the likelihood of diversification (Caves et al., 1980; Lemelin, 1982). The larger the firm size, the greater the constraints on growth, or the larger the stock of lumpy assets that can be exploited by diversification. Baldwin (1995) found that there is a more or less random growth process at work in the manufacturing population, except in the smallest and the largest firms. The largest firms face an upward bound in individual markets because of limited market size, that is, they have truncated growth possibilities in their home markets. As a result, they are posited to have a higher likelihood of entering other markets via the diversification process. Size may also be associated with diversification if large firms face lower financing costs and can expand more cost effectively through acquisition. Finally, size may confer scope advantages that are enhanced with the purchase of complementary product lines and assets in related industries. Hypotheses about growth and specialized assets have received considerable attention in previous empirical studies (Gort, 1962; Amey, 1964; Gorecki, 1975; Caves et al., 1980).

Other research has emphasized the role that inter-industry economic relationships (i.e., vertical linkages) play in conditioning diversification strategies. Following MacDonald (1985) and Lemelin (1982), we use information on inter-industry trade flows to quantify the relative significance of these economic relationships. Two variables are used to capture these effects.

The first variable (LINK) is the number of primary forward and backward linkages connecting the industry to other sectors. Recall that these linkages - defined using a $20 \%$ threshold represent significant economic relationships, either in terms of satisfying input requirements (backward linkages) or distributing outputs (forward linkages). We posit that industries with large numbers of these linkages are more likely to contain diversified firms or to encourage, on average, higher levels of diversification per firm. This reflects a greater potential for vertically integrated strategies in well connected sectors.

The second variable (INDENT) is a summary statistic that combines inter-industry purchase and sales information to measure whether these inter-industry linkages are important. We adopt an entropy-based statistic that takes the form: ${ }^{43}$

$$
\operatorname{INDENT}_{i}=\sum_{i}^{N} s_{i} \log \left(1 / s_{i}\right)
$$

where

\footnotetext{
${ }^{43}$ For discussion of this metric, see Baldwin and Peters (2000).
} 
$N=$ number of linkages; and

$S_{i}=$ share of purchases of sales from industry $i$.

This metric was calculated separately for backward and forward linkages and then summed to create a total entropy measure from the two. The higher this value, the more diversified is an industry's purchases from, and sales to, other sectors. We posit that trade flows are positively associated with diversification strategies at the level of the firm.

Finally, we include a dummy variable for the goods-producing industries (GOODS) to test whether there are greater forces leading to diversification in goods-producing industries than in service industries.

\subsection{Regression results}

In our first regression exercise, the sample consists of 132 private sector industries distributed across the goods-producing and market services sectors. Least squares parameter estimates are reported in Table 6.2.1.

Table 6.2.1: OLS regression results, business sector (goods and market services)

\begin{tabular}{lccc}
\hline & $\begin{array}{c}\text { Model 1: } \\
\text { Dependent Variable } \\
(\text { TOTAL })\end{array}$ & $\begin{array}{c}\text { Model 2: } \\
\text { Dependent Variable } \\
\left(\text { AVERAGE } \text { 10 }^{4}\right)\end{array}$ & $\begin{array}{c}\text { Model 3: } \\
\text { Dependent Variable } \\
(\text { PERCENT) }\end{array}$ \\
\hline INTERCEPT & 9.329 & -14.720 & -0.204 \\
GWTH & 0.044 & 0.387 & -0.016 \\
CONC & -0.076 & $0.964 * * *$ & $0.035^{* * *}$ \\
MGMT & -0.589 & -0.640 & -0.134 \\
TWKR & -0.210 & -0.261 & 0.004 \\
ADVT & 65.127 & -58.830 & 10.969 \\
LINK & $0.757^{*}$ & 0.057 & -0.029 \\
INDENT & $0.448^{* * *}$ & -0.337 & -0.014 \\
AVGESIZE & -0.003 & $0.280^{* * *}$ & $0.011^{* * *}$ \\
GOODS & $-14.611^{* * *}$ & $39.70^{*}$ & $1.783^{* *}$
\end{tabular}

Summary Statistics:
Adjusted $\mathrm{R}^{2}$
0.27
0.44
0.56
Number of observations
132
132
132

$* * *$ Significant at $1 \%, * *$ significant at $5 \%, *$ significant at $10 \%$ 
In model 1, only those factors related to inter-industry trade flows (LINK and INDENT) influence diversification patterns. More diversified inter-industry trade linkages - as reflected in the variable (INDENT) which captures the sales to, and purchases from, other industries - lead to higher levels of total (employment-based) diversification. There is weak evidence that the number of these significant inter-industry linkages (LINK) is also positively associated with diversification levels. All other explanatory factors - pertaining to knowledge intensity, constrained optimization, specialized assets, and firm size - have no statistical influence on levels of total diversification. Finally, goods industries have lower levels of diversification than service industries.

A different picture emerges in model 2, which examines factors that, on average, encourage firms to become more diversified. Here the intensity of inter-sectoral trade flows (LINK and INDENT) has no significant effect. Concentration and firm size, however, are positively associated with average diversification. Both results are consistent with the constrained optimization hypothesis which holds that limited market space in primary business lines forces firms to diversify into other sectors. We also find weak evidence that firms in goods-producing industries become, on average, more diversified than those in services.

The results for model 3 mirror those of model 2. Concentration and average firm size are positively associated with the percentage of firms within an industry that diversify. Other variables, including trade flows, have no effect. The percentage of firms that diversify is higher in goods industries than in services.

Several conclusions emerge from this initial exercise.

First, some support for the constrained optimization hypothesis is apparent - average firm size and concentration are positively associated with diversification. But we see that each is related to the percentage of firms within an industry that diversify, and to the average amount of diversification within a firm. Concentration and firm size, however, are not related to total diversification, probably because industries that are concentrated or that have large firm sizes have fewer businesses upon which to base calculations of total entropy. Our findings bring additional evidence to bear on a mixed historical record. While Gort (1962) found a positive association between concentration and diversification among US manufacturing industries, Gorecki (1975), studying UK manufacturing, found no evidence to support this view. Our results are consistent with the US findings.

Second, inter-industry trade linkages condition diversification patterns. Industries with larger numbers of significant inter-industry links and with more diversified trade flows are more likely to have higher total entropy measures. But trade characteristics do not affect the average level of diversification within the firm, nor the percentage of firms within an industry that diversify. Their effect is felt on the number of firms that diversify. 
Third, sectoral differences are apparent. The amount of total diversification in services industries is higher than in goods industries. There is some evidence, however, that firms in the goods sector are, on average, more diversified than those in services, and stronger evidence that the percentage of firms in the goods sector that diversify is greater than in services.

Fourth, in contrast to earlier findings, we find no evidence that knowledge-based assets (MGMT and TWKR), advertising intensity (ADVT) or growth rates (GRWTH) condition diversification patterns. ${ }^{44}$ These factors had no statistically significant effect on any of the dependent variables total diversification, average diversification or the percentage of firms that diversify. The finding that technical characteristics are not closely related to diversification is at odds with US studies by Gort (1962) and Amey (1964). Evidence for the UK that corroborates the US result is found by Gorecki (1975) and Grant (1977). Our results, based on a broad sample of goods and services industries, do not support these earlier findings. The reason for this may simply rest with the open nature of the Canadian economy and the extent of foreign control. Diversification is presently measured in terms of Canadian rather than North American operations, which may obscure the connection between knowledge-based assets and diversification. The absence of significant effects on industry growth and advertising intensity is less curious given the mixed historical record of other studies. While Gort (1962) observed growth effects, Gorecki found little evidence that growth affects diversification patterns in any systematic manner. Our results on advertising intensity concur with Grant (1977), but differ with Gorecki (1975) who observed a negative relationship between marketing intensity and diversification.

Comparisons to previous studies may be of limited utility in that our industry mix extends well beyond the manufacturing sector, while most early studies are limited to manufacturing industries (e.g., Gort, 1962; Gorecki, 1975; Grant, 1977). If the determinants of diversification should differ systematically between manufactures and other industries, the above comparisons may obscure important differences. To examine this, we re-estimated our three regressions limiting our sample to manufacturing industries. This reduces the set of observations from 132 to 90. Since all manufacturing industries are goods-producing industries, the (GOODS) variable was dropped. We present our results in Table 6.2.2.

Our results for average diversification (model 2) and the percentage of firms that diversify (model 3) are identical to those reported earlier - once again concentration and average firm size exert positive and significant effects. No other explanatory variables (common to both models) are statistically significant. For total diversification (model 1), two differences warrant emphasis. First, concentration is now significant, and negatively associated with total log entropy. Second, the directionality of the trade entropy variable (INDENT) is reversed. While our results for the goods and services sample indicated that more diversified trade flows lead to more total (employment) diversification, results for manufacturing provide weak evidence to the contrary more diversified trade flows lead to less total diversification.

\footnotetext{
${ }^{44}$ We also experimented with an R\&D-to-sales ratio to evaluate the significance of knowledge assets. Here too, no significant relationships were observed.
} 
Table 6.2.2: OLS regression results, manufacturing industries

\begin{tabular}{|c|c|c|c|}
\hline & $\begin{array}{c}\text { Model 1: } \\
\text { Dependent Variable } \\
(\text { TOTAL })\end{array}$ & $\begin{array}{c}\text { Model 2: } \\
\text { Dependent Variable } \\
\left(\text { AVERAGE } X 10^{4}\right)\end{array}$ & $\begin{array}{c}\text { Model 3: } \\
\text { Dependent Variable } \\
(\text { PERCENT })\end{array}$ \\
\hline INTERCEPT & $6.855^{* * *}$ & -3.250 & -0.277 \\
\hline GWTH & 0.191 & -2.70 & -0.102 \\
\hline $\mathrm{CONC}$ & $-0.060 * * *$ & $0.995 * * *$ & $0.035 * * *$ \\
\hline MGMT & -0.069 & 7.230 & 0.269 \\
\hline TWKR & 0.002 & 0.404 & 0.007 \\
\hline ADVT & -5.974 & -390.52 & 2.715 \\
\hline LINK & $0.272 *$ & 0.131 & 0.034 \\
\hline INDENT & $-0.051^{*}$ & -0.669 & -0.027 \\
\hline AVGESIZE & 0.001 & $0.254 * * *$ & $0.008 * * *$ \\
\hline \multicolumn{4}{|l|}{ Summary Statistics: } \\
\hline Adjusted $\mathrm{R}^{2}$ & 0.19 & 0.40 & 0.44 \\
\hline Number of observations & 90 & 90 & 90 \\
\hline
\end{tabular}

*** Significant at $1 \%, * *$ significant at $5 \%, *$ significant at $10 \%$

\section{Conclusions}

Diversification is an important element of corporate strategy. Firms diversify by expanding the scope of their activities - by establishing or acquiring operating units in different industrial sectors. Several factors can motivate a decision to diversify. These include inter alia (i) the need to capitalize on vertical efficiencies by establishing control over discrete elements of the production and distribution chain; (ii) the desire to acquire and take advantage of special assets such as R\&D; and (iii) the need to spread risk over different product markets in order to reduce exposure to demand shocks.

Diversification strategies can affect an industry's competitive balance. By entering different markets, firms can acquire additional market power, gain scale advantages, and employ assetswitching strategies. This said, the historical record on post-diversification performance is, at best, mixed. In certain cases, diversification leads to sharp gains in profitability or productivity; in others, such benefits may be ephemeral or altogether absent. Like all elements of business strategies, diversification involves a risky gamble - one whose odds depend principally on the underlying competencies of individual firms.

This paper provides a comprehensive study of diversified firms in the Canadian economy. It examines the quantitative magnitude of diversification in Canadian industries and the types of diversification strategies that prevail - whether diversification occurs across broad or narrow 
industrial groupings, and whether diversification is more (or less) apparent across industries that maintain strong economic relationships. It also asks whether observed patterns of diversification are related to certain industry characteristics.

We review our principal findings below.

Most diversification in the Canadian economy is horizontal and broad-spectrum. Over eighty percent of corporate diversification occurs into sectors that do not have significant trade flows. Seventy-one percent occurs across 2-digit industry groups. Taken together, these two dimensions account for just under $60 \%$ of the economy total. This suggests that, in the main, risk management and asset acquisition strategies play a more significant role than strategies designed to improve vertical efficiencies along the production and distribution chain. For many diversified firms, however, such objectives are not likely to be mutually exclusive. Large and complex businesses tend to have both horizontally and vertically integrated components in their operating structures.

Sectoral differences are apparent. When the employment characteristics of all multi-unit firms are accounted for, those in goods industries are, on average, more industrially diversified than those in market services. If, however, we adopt a metric designed to highlight geographic factors, multi-unit firms in services are the more diversified.

More conventional measures of diversification that focus strictly on firms with operating units in two or more industries convey similar patterns across the goods and services sectors. This is due to the fact that a relatively greater share of multi-unit service firms favour geographic over industrial diversification. Our multivariate analysis suggests that firms in goods industries are, on average, more industrially diversified than those in services, and that a greater percentage of firms in goods-producing industries pursue diversification strategies.

Overall diversification patterns across goods and services are influenced by inter-sectoral trade flows. Industries with more diversified trade linkages have higher levels of employment diversification - driven by the number of firms that adopt diversification strategies. However, trade patterns have no significant effect on average levels of diversification, nor on the percentage of firms within an industry that diversify.

Concentration and average firm size are positively associated with diversification patterns specifically, average levels of diversification per firm and the percentage of firms within an industry that pursue diversification strategies. These results are consistent with the constrained optimization hypothesis - firms diversify into other sectors when the potential for growth along the primary business line is exhausted - or with the notion that larger firms possess special knowledge assets. However, advertising intensity, knowledge assets and industry growth factors that are widely posited to affect diversification patterns - have no significant influence, either in the business sector as a whole or more narrowly within manufacturing industries. 


\section{Appendix A: Definition of Firm}

The concept used in this study to define a firm is based on the notion of a Business Entity developed by the Business Register of Statistics Canada:

The Business Entity represents an economic transactor having the responsibility and the authority to allocate resources in the production of goods and services, thereby directing and managing the receipt and disposition of income, the accumulation of property, borrowing and lending, and maintaining a complete set of financial statements accounting for these responsibilities.

The basic criteria of the Business Entity are as follows:

1. Autonomy indicates that the Business Entity is an independent economic unit:

1.1 The Business Entity transacts at arms' length; and

1.2 The Business Entity has the authority to make business and operating decisions.

2. Ownership indicates that the Business Entity must be owned either by one or more legal entities.

2.1 The Business Entity's ownership legal base is composed of one of the following groups:

2.1.1 A single legal entity representing an independent incorporated Canadian Legal Entity that is neither owned nor controlled by another Canadian incorporated Legal Entity, and also, neither owns nor controls any other Canadian incorporated legal entity.

2.1.2 A single legal entity representing a Canadian subsidiary which does not own any other Canadian legal entity.

2.1.3 A group of legal entities commonly owned and controlled (through Parent/Subsidiary relationships).

2.2 Two or more legal entities (not as a group) for Unincorporated Joint Venture/ Partnership (UJV/PS).

2.3 A foreign Legal Entity for a Canadian Branch Entity's operations.

3. Management indicates that the Business Entity manages one or more production entities.

4. Residence indicates that these Production Entities are operating in Canada.

5. Accounting indicates that the Business Entity has the financial reporting capability whereby it can produce annual financial statements for its business situation and the results of its operations.

5.1 Annual financial statements indicate that the Business Entity prepares at minimum a balance sheet and an income statement.

5.2 In the case of the Business Entity which is composed of a group of legal entities it is required that the financial statements reflect the elimination of all inter-company accounts and transactions within the group. 
Of the 13,421 multi-unit firms in the Business Register ( $3^{\text {rd }}$ Quarter, 1998), all but 1,100 are single legal entity firms. Within the set of 1,100 multi legal entity firms, over $90 \%$ are legal consolidations; of the remainder, partnerships outnumber UJVs 5 to 1. 


\section{References}

Abbott, T.A. and S.H. Andrews. 1990. The Classification of Manufacturing Industries: An InputBased Clustering of Activity. Discussion Paper 90-7. Center for Economic Studies. US Bureau of the Census.

Amey, L.R. 1964. "Diversified Manufacturing Businesses," Journal of the Royal Statistical Society, series A, 127: 251-90.

Amit, R. and J. Livnat. 1988. "A Concept of Conglomerate Diversification," Journal of Management 14, 4: 593-604.

Aw, B.Y. and G. Batra. 1998. "Firm size and the pattern of diversification," International Journal of Industrial Organization, 16-3: 313-331.

Baldwin, J.R. 1995. The Dynamics of Industrial Competition: A North American Perspective. Cambridge: Cambridge University Press.

Baldwin, J.R, Beckstead, D. and R.E. Caves. 2000. Changes in the Diversification of Canadian Manufacturing Firms (1973-1997). Research Paper. Analytical Studies Branch. Ottawa: Statistics Canada. Forthcoming.

Baldwin, J.R. and R.E. Caves. 1991. "Foreign Multinational Enterprises and Merger Activity in Canada," In Corporate Globalization through Mergers and Acquisitions. Edited by L. Waverman. Calgary: University of Calgary Press.

Baldwin, J.R. and A. Peters. 2000. Innovation and Connectivity: The Nature of Market Linkages and Innovation Networks in Canadian Manufacturing Industries. Research Paper. Analytical Studies Branch. Ottawa: Statistics Canada. Forthcoming.

Berry, C. 1975. Corporate Growth and Diversification. Princeton: Princeton University Press.

Caves, R.E. 1975. Diversification, Foreign Investment and Scale in North American Manufacturing Industries. Ottawa: Economic Council of Canada.

Caves, R.E. 1987. " Effects of Mergers and Acquisition on the Economy: An Industrial Organization Perspective." In The Merger Boom. Edited by Lynne Brown and Eric Rosengreen. Boston: Federal Reserve Bank of Boston. 149-68

Caves, R.E., M. Porter, A.M. Spence, with J.T Scott. 1980. Competition in the Open Economy. Cambridge, Mass: Harvard University Press.

Clarke, R. 1985. Industrial Economics. Oxford: Basil Blackwell. 
Clarke R. and S.W. Davies. 1983. "Aggregate Concentration, Market Concentration and Diversification," Economic Journal 93: 182-92.

Cowling, K., P. Stoneman, J. Cubbin, J. Cable, G. Hall, S. Domberger and P. Dutton. 1980. Mergers and Economic Performance. Cambridge: Cambridge University Press.

Davies, S.W. and C. Morris. 1995. "A new index of vertical integration: Some estimates for UK manufacturing," International Journal of Industrial Organization, 13-2: 151-177.

Eckbo, B.E. 1986. "Mergers and the Market for Corporate Control: The Canadian Evidence," Canadian Journal of Economics 19: 236-60.

Eckbo, B.E. 1988. "The Market for Corporate Control: Policy Issues and Capital Market Evidence," In Mergers, Corporate Concentration and Power in Canada. Edited by R. S Khemani, D. M Shapiro and W.T Stanbury. Halifax: Institute for Public Policy. 143-225.

Federal Trade Commission. Staff Report. 1972. Conglomerate Merger Performance: An Empirical Analysis of Nine Corporations. Washington: Federal Trade Commission.

Gorecki, P.K. 1975. "An Inter-Industry Analysis of Diversification in the UK "Manufacturing Sector” Journal of Industrial Economics 24: 131-46.

Gort, M. 1962. Diversification and Integration in American Industry. Princeton University Press.

Grant, R.M. 1977. "The Determinants of the Inter-Industry Pattern of Diversification by UK Manufacturing Industries," Bulletin of Economic Research 29: 84-95.

Hall, E.H. and C.H. St. John. 1994. "A Methodological Note on Diversity Measurement," Strategic Management Journal, 15-2: 153-168.

Jacquemin, A.P. and C.H. Berry. 1979. "Entropy Measures of Corporate Growth," The Journal of Industrial Economics 27: 359-69.

Jog, V.J. and A.L. Riding. 1988. "Post-Acquisition Performance of Partially Acquired Canadian Firms" In Mergers, Corporate Concentration and Power in Canada. Edited by R.S Khemani, D. M. Shapiro and W.T Stanbury. Halifax: Institute for Public Policy. 143-225.

Kim, W.C. 1989. "Developing a Global Diversification Measure," Management Science, 35-3: 376-383.

Lecraw, D.J. 1977. Conglomerate Mergers in Canada. Royal Commission on Corporate Concentration. Study No. 32. Ottawa: Minister of Supply and Services Canada.

Lecraw, D.J. 1984. "Diversification Strategy and Performance," Journal of Industrial Economics, 33-2: 179-198. 
Lemelin, A. 1982. "Relatedness in the Patterns of Interindustry Diversification," Review of Economics and Statistics, 64-4: 646-657.

Lichtenberg, F.R. 1992. Corporate Takeovers and Productivity. Cambridge, Mass.: MIT Press.

MacDonald, J.M. 1984. "Diversification, Market Growth, and Concentration in United States Manufacturing," Southern Economic Journal, 50-4: 1098-1111.

MacDonald, J.M. 1985. "R and D and the Directions of Diversification," Review of Economics and Statistics," 67-4: 538-590.

Maddigan, R.J. 1981. "The Measurement of Vertical Integration," Review of Economics and Statistics, 63-3: 328-335.

Marris, R. 1964. The Economic Theory of Managerial Capitalism. New York: Free Press.

Martin, S. 1986. "Causes and Effects of Vertical Integration,” Applied Economics, 18-7: 737755.

Miller, R.A. 1969. "Market Structure and Industrial Performance: Relation of Profit Rate to Concentration, Advertising Intensity and Diversity," Journal of Industrial Economics 17: 104118.

Montgomery, C.A. 1994. "Corporate Diversification," Journal of Economic Perspectives 8, 3: 163-78.

Mueller, D.C. 1987. The Corporation; Growth, Diversification and Mergers. London: Harwood.

Penrose, E.T. 1959. The Theory of the Growth of Firms. Oxford: Blackwell.

Pomfret, R. and D. Shapiro. 1980. "Firm Size, Diversification, and Profitability of Large Corporations in Canada," Journal of Economic Studies, 7-3: 140-150.

Ramanujam, V. and P. Varadarajan. 1989. Research on Corporate Diversification: A Synthesis," Strategic Management Journal 10: 523-551.

Ravenscraft, D. and F.M. Scherer. 1987. Mergers, Sell-Offs and Economic Efficiency. Washington, D.C.: Brookings.

Rhoades, S.A. 1973. "The Effect of Diversification on Industry Profit Performance in 241 Manufacturing Industries:1963," Review of Economics and Statistics 55: 146-155.

Rhoades, S.A. 1974. "A Further Evaluation of the Effect of Diversification on Industry Profit Performance," Review of Economics and Statistics 56: 557-59. 
Roelandt, T., den Hertog, P., van Sinderen, J. and Vollaard, B. 1997. Cluster analysis and cluster policy in the Netherlands: Position paper. Presented at the OECD workshop on Cluster analysis and cluster policy. Amsterdam, October 1997.

Royal Commission on Corporate Concentration. Report 1978. Ottawa: Minister of Supply and Services Canada

Rumelt, R. 1974. Strategy, Structure and Economic Performance. Boston: Harvard Business School Division of Research.

Scherer, F.M. 1988. "Corporate Takeovers: The Efficiency Arguments," Journal of Economic Perspectives 2: 69-82.

Tarasofsky, A. with Ronald Corvari. 1991. Corporate Mergers and Acquisitions; Evidence of Profitability. Ottawa: Economic Council of Canada.

Vachani, S. 1991. "Distinguishing Between Related and Unrelated International Geographic Diversification - A Comprehensive Measure of Global Diversification," Journal of International Business Studies, 22-2: 307-322.

Williamson, O. 1975. Markets and Hierarchies. New York: Free Press.

Yotopoulos, P.A. and J.B. Nugent. 1973. "A Balanced-Growth Version of the Linkage Hypothesis: A Test," Quarterly Journal of Economics, LXXXVII-2: 157-71. 


\section{ANALYTICAL STUDIES BRANCH \\ RESEARCH PAPER SERIES}

No. 1 Behavioural Response in the Context of Socio-Economic Microanalytic Simulation, Lars Osberg (April 1986)

No. 2 Unemployment and Training, Garnett Picot (1987)

No. 3 Homemaker Pensions and Lifetime Redistribution, Michael Wolfson (August 1987)

No. 4 Modeling the Lifetime Employment Patterns of Canadians, Garnett Picot (Winter 1986)

No. 5 Job Loss and Labour Market Adjustment in the Canadian Economy, Garnett Picot and Ted Wannell (1987)

No. 6 A System of Health Statistics: Toward a New Conceptual Framework for Integrating Health Data, Michael C. Wolfson (March 1990)

No. 7 A Prototype Micro-Macro Link for the Canadian Household Sector, Hans J. Adler and Michael C. Wolfson (August 1987)

No. 8 Notes on Corporate Concentration and Canada's Income Tax, Michael C. Wolfson (October 1987)

No. 9 The Expanding Middle: Some Canadian Evidence on the Deskilling Debate, John Myles (Fall 1987)

No. 10 The Rise of the Conglomerate Economy, Jorge Niosi (1987)

No. 11 Energy Analysis of Canadian External Trade: 1971 and 1976, K.E. Hamilton (1988)

No. 12 Net and Gross Rates of Land Concentration, Ray D. Bollman and Philip Ehrensaft (1988)

No. 13 Cause-Deleted Life Tables for Canada (1972 to 1981): An Approach Towards Analyzing Epidemiological Transition, Dhruva Nagnur and Michael Nagrodski (November 1987)

No. 14 The Distribution of the Frequency of Occurrence of Nucleotide Subsequences, Based on Their Overlap Capability, Jane F. Gentleman and Ronald C. Mullin (1988)

No. 15 Immigration and the Ethnolinguistic Character of Canada and Quebec, Réjean Lachapelle (1988)

No. 16 Integration of Canadian Farm and Off-Farm Markets and the Off-Farm Work of Women, Men and Children, Ray D. Bollman and Pamela Smith (1988)

No. 17 Wages and Jobs in the 1980s: Changing Youth Wages and the Declining Middle, J. Myles, G. Picot and T. Wannell (July 1988)

No. 18 A Profile of Farmers with Computers, Ray D. Bollman (September 1988)

No. 19 Mortality Risk Distributions: A Life Table Analysis, Geoff Rowe (July 1988)

No. 20 Industrial Classification in the Canadian Census of Manufactures: Automated Verification Using Product Data, John S. Crysdale (January 1989) 
No. 21 Consumption, Income and Retirement, A.L. Robb and J.B. Burbridge (1989)

No. 22 Job Turnover in Canada's Manufacturing Sector, John R. Baldwin and Paul K. Gorecki (Summer 1989)

No. 23 Series on The Dynamics of the Competitive Process, John R. Baldwin and Paul K. Gorecki (1990)
A. Firm Entry and Exit Within the Canadian Manufacturing Sector.
B. Intra-Industry Mobility in the Canadian Manufacturing Sector.
C. Measuring Entry and Exit in Canadian Manufacturing: Methodology.
D. The Contribution of the Competitive Process to Productivity Growth: The Role of Firm and Plant Turnover.
E. Mergers and the Competitive Process.
F. n/a
G. Concentration Statistics as Predictors of the Intensity of Competition.
H. The Relationship Between Mobility and Concentration for the Canadian Manufacturing Sector.

No. 24 Mainframe SAS Enhancements in Support of Exploratory Data Analysis, Richard Johnson, Jane F. Gentleman and Monica Tomiak (1989)

No. 25 Dimensions of Labour Market Change in Canada: Intersectoral Shifts, Job and Worker Turnover, John R. Baldwin and Paul K. Gorecki (1989)

No. 26 The Persistent Gap: Exploring the Earnings Differential Between Recent Male and Female Postsecondary Graduates, Ted Wannell (1989)

No. 27 Estimating Agricultural Soil Erosion Losses From Census of Agriculture Crop Coverage Data, Douglas F. Trant (1989)

No. 28 Good Jobs/Bad Jobs and the Declining Middle: 1967-1986, Garnett Picot, John Myles, Ted Wannel (1990)

No. 29 Longitudinal Career Data for Selected Cohorts of Men and Women in the Public Service, 1978-1987, Garnett Picot and Ted Wannell (1990)

No. 30 Earnings and Death-Effects Over a Quarter Century, Michael Wolfson, Geoff Rowe, Jane F. Gentleman and Monica Tomiak (1990)

No. 31 Firm Response to Price Uncertainty: Tripartite Stabilization and the Western Canadian Cattle Industry, Theodore M. Horbulyk (1990)

No. 32 Smoothing Procedures for Simulated Longitudinal Microdata, Jane F. Gentleman, Dale Robertson and Monica Tomiak (1990)

No. 33 Patterns of Canadian Foreign Direct Investment Abroad, Paul K. Gorecki (1990)

No. 34 POHEM - A New Approach to the Estimation of Health Status Adjusted Life Expectancy, Michael C. Wolfson (1991)

No. 35 Canadian Jobs and Firm Size: Do Smaller Firms Pay Less?, René Morissette (1991)

No. 36 Distinguishing Characteristics of Foreign High Technology Acquisitions in Canada's Manufacturing Sector, John R. Baldwin and Paul K. Gorecki (1991)

No. 37 Industry Efficiency and Plant Turnover in the Canadian Manufacturing Sector, John R. Baldwin (1991) 
No. 38 When the Baby Boom Grows Old: Impacts on Canada's Public Sector, Brian B. Murphy and Michael C. Wolfson (1991)

No. 39 Trends in the Distribution of Employment by Employer Size: Recent Canadian Evidence, Ted Wannell (1991)

No. 40 Small Communities in Atlantic Canada: Their Industrial Structure and Labour Market Conditions in the Early 1980s, Garnett Picot and John Heath (1991)

No. 41 The Distribution of Federal/Provincial Taxes and Transfers in Rural Canada, Brian B. Murphy (1991)

No. 42 Foreign Multinational Enterprises and Merger Activity in Canada, John Baldwin and Richard Caves (1992)

No. 43 Repeat Users of the Unemployment Insurance Program, Miles Corak (1992)

No. 44 POHEM -- A Framework for Understanding and Modeling the Health of Human Populations, Michael C. Wolfson (1992)

No. 45 A Review of Models of Population Health Expectancy: A Micro-Simulation Perspective, Michael C. Wolfson and Kenneth G. Manton (1992)

No. 46 Career Earnings and Death: A Longitudinal Analysis of Older Canadian Men, Michael C. Wolfson, Geoff Rowe, Jane Gentleman and Monica Tomiak (1992)

No. 47 Longitudinal Patterns in the Duration of Unemployment Insurance Claims in Canada, Miles Corak (1992)

No. 48 The Dynamics of Firm Turnover and the Competitive Process, John Baldwin (1992)

No. 49 Development of Longitudinal Panel Data from Business Registers: Canadian Experience, John Baldwin, Richard Dupuy and William Penner (1992)

No. 50 The Calculation of Health-Adjusted Life Expectancy for a Canadian Province Using a Multi-Attribute Utility Function: A First Attempt, J.-M. Berthelot, R. Roberge and M.C. Wolfson (1992)

No. 51 Testing the Robustness of Entry Barriers, J. R. Baldwin and M. Rafiquzzaman (1993)

No. 52 Canada's Multinationals: Their Characteristics and Determinants, Paul K. Gorecki (1992)

No. 53 The Persistence of Unemployment: How Important were Regional Extended Unemployment Insurance Benefits? Miles Corak, Stephen Jones (1993)

No. 54 Cyclical Variation in the Duration of Unemployment Spells, Miles Corak (1992)

No. 55 Permanent Layoffs and Displaced Workers: Cyclical Sensitivity, Concentration, and Experience Following the Layoff, Garnett Picot and Wendy Pyper (1993)

No. 56 The Duration of Unemployment During Boom and Bust, Miles Corak (1993)

No. 57 Getting a New Job in 1989-90 in Canada, René Morissette (1993)

No. 58 Linking Survey and Administrative Data to Study Determinants of Health, P. David, J.-M. Berthelot and C. Mustard (1993)

No. 59 Extending Historical Comparability in Industrial Classification, John S. Crysdale (1993) 
No. 60 What is Happening to Earnings Inequality in Canada?, R. Morissette, J. Myles and G. Picot (June 1994)

No. 61 Structural Change in the Canadian Manufacturing Sector, (1970-1990), J. Baldwin and M. Rafiquzzaman (July 1994)

No. 62 Unemployment Insurance, Work Disincentives, and the Canadian Labour Market: An Overview, Miles Corak (January 1994)

No. 63 Recent Youth Labour Market Experiences in Canada, Gordon Betcherman and René Morissette (July 1994)

No. 64 A Comparison of Job Creation and Job Destruction in Canada and the United States, John Baldwin, Timothy Dunne and John Haltiwanger (July 1994)

No. 65 What is Happening to Weekly Hours Worked in Canada?, René Morissette and Deborah Sunter (June 1994)

No. 66 Divergent Inequalities -- Theory, Empirical Results and Prescriptions, Michael C. Wolfson (May 1995)

No. 67 XEcon: An Experimental / Evolutionary Model of Economic Growth, Michael C. Wolfson (June 1995)

No. 68 The Gender Earnings Gap Among Recent Postsecondary Graduates, 1984-92, Ted Wannell and Nathalie Caron (November 1994)

No. 69 A Look at Employment-Equity Groups Among Recent Postsecondary Graduates: Visible Minorities, Aboriginal Peoples and the Activity Limited, Ted Wannell and Nathalie Caron (November 1994)

No. 70 Employment Generation by Small Producers in the Canadian Manufacturing Sector, John R. Baldwin and Garnett Picot (November 1994)

No. 71 Have Small Firms Created a Disproportionate Share of New Jobs in Canada? A Reassessment of the Facts, Garnett Picot, John Baldwin and Richard Dupuy (November 1994)

No. 72 Selection Versus Evolutionary Adaptation: Learning and Post-Entry Performance, J. Baldwin and M. Rafiquzzaman (May 1995)

No. 73 Business Strategies in Innovative and Non-Innovative Firms in Canada, J. Baldwin and J. Johnson (February 1995)

No. 74 Human Capital Development and Innovation: The Case of Training in Small and Medium Sized-Firms, J. Baldwin and J. Johnson (March 1995)

No. 75 Technology Use and Industrial Transformation: Emprirical Perspectives, John Baldwin, Brent Diverty and David Sabourin (August 1995)

No. 76 Innovation: The Key to Success in Small Firms, John R. Baldwin (February 1995)

No. 77 The Missing Link: Data on the Demand side of Labour Markets, Lars Osberg (April 1995)

No. 78 Restructuring in the Canadian Manufacturing Sector from 1970 to 1990: Industry and Regional Dimensions of Job Turnover, J. Baldwin and M. Rafiquzzaman (July 1995)

No. 79 Human Capital and the Use of Time, Frank Jones (June 1995)

No. 80 Why Has Inequality in Weekly Earnings Increased in Canada? René Morissette (July 1995) 
No. 81 Socio-Economic Statistics and Public Policy: A New Role For Microsimulation Modeling, Michael C. Wolfson (July 1995)

No. 82 Social Transfers, Changing Family Structure, and Low Income Among Children, Garnett Picot and John Myles (September 1995)

No. 83 Alternative Measures of the Average Duration of Unemployment, Miles Corak and Andrew Heisz (October 1995)

No. 84 The Duration of Unemployment: A User Guide, Miles Corak and Andrew Heisz (December 1995)

No. 85 Advanced Technology Use in Manufacturing Establishments, John R. Baldwin and Brent Diverty (November 1995)

No. 86 Technology Use, Training and Plant-Specific Knowledge in Manufacturing Establishments, John R. Baldwin, Tara Gray and Joanne Johnson (December 1995)

No. 87 Productivity Growth, Plant Turnover and Restructuring in the Canadian Manufacturin Sector, John R. Baldwin (November 1995)

No. 88 Were Small Producers the Engines of Growth in the Canadian Manufacturing Sector in the 1980s?, John R. Baldwin (October 1996)

No. 89 The Intergenerational Income Mobility of Canadian Men, Miles Corak and Andrew Heisz (January 1996)

No. 90 The Evolution of Payroll Taxes in Canada: 1961 - 1993, Zhengxi Lin, Garnett Picot and Charles Beach (February 1996)

No. 91 Project on Matching Census 1986 Database and Manitoba Health Care Files: Private Households Component, Christian Houle, Jean-Marie Berthelot, Pierre David, Cam Mustard, D.Sc., Roos L, PhD and M.C. Wolfson, PhD (March 1996)

No. 92 Technology-induced Wage Premia in Canadian Manufacturing Plants during the 1980s, John Baldwin, Tara Gray and Joanne Johnson (December 1996)

No. 93 Job Creation by Company Size Class: Concentration and Persistence of Job Gains and Losses in Canadian Companies, Garnett Picot and Richard Dupuy (April 1996)

No. 94 Longitudinal Aspects of Earnings Inequality in Canada, René Morissette and Charles Bérubé (July 1996)

No. 95 Changes in Job Tenure and Job Stability in Canada, Andrew Heisz (November 1996)

No. 96 Are Canadians More Likely to Lose Their Jobs in the 1990s? Garnett Picot and Zhengxi Lin (August 6, 1997)

No. 97 Unemployment in the Stock and Flow, Michael Baker, Miles Corak and Andrew Heisz (September1996)

No. 98 The Effect of Technology and Trade on Wage Differentials Between Nonproduction and Production Workers in Canadian Manufacturing, John R. Baldwin and Mohammed Rafiquzzaman (May 1998)

No. 99 Use of POHEM to Estimate Direct Medical Costs of Current Practice and New Treatments Associated with Lung Cancer in Canada, C. Houle, B. P. Will, J.-M. Berthelot, Dr. W.K. Evans (May 1997)

No. 100 An Experimental Canadian Survey That Links Workplace Practices and Employee Outcomes: Why it is Needed and How it Works, Garnett Picot, Ted Wannell (May 1997) 
No. 101 Innovative Activity in Canadian Food Processing Establishments: The Importance of Engineering Practices, John Baldwin and David Sabourin (November 1999)

No. 102 Differences in Strategies and Performances of Different Types of Innovators, John R. Baldwin and Joanne Johnson (December 1997)

No. 103 Permanent Layoffs in Canada: Overview and Longitudinal Analysis Garnett Picot, Zhengxi Lin, and Wendy Pyper (September, 1997)

No. 104 Working More? Working Less? What do Canadian Workers Prefer?, Marie Drolet and René Morissette (May 20, 1997)

No. 105 Growth of Advanced Technology Use in Canadian Manufacturing During the 1990's, John Baldwin, Ed Rama and David Sabourin (December 14, 1999)

No. 106 Job Turnover and Labour Market Adjustment in Ontario from 1978 to 1993, Zhengxi Lin and Wendy Pyper (1997)

No. 107 The Importance of Research and Development for Innovation in Small and Large Canadian Manufacturing Firms, John R. Baldwin (September 24, 1997)

No. 108 International Competition and Industrial Performance: Allocative Efficiency, Productive Efficiency, and Turbulence, John R. Baldwin and Richard E. Caves (October 1997)

No. 109 The Dimensions of Wage Inequality among Aboriginal Peoples, Rachel Bernier (December 1997)

No. 110 Trickling Down or Fizzling Out? Economic Performance, Transfers, Inequality and Low Income, Myles Zyblock and Zhengxi Lin (December 10, 1997)

No. 111 Corporate Financial Leverage: A Canada - U.S. Comparison, 1961-1996, Myles Zyblock (December 1997)

No. 112 An explanation of the Increasing Age Premium, Constantine Kapsalis (July 1998)

No. 113 The Intergenerational Earnings and Income Mobility of Canadian Men: Evidence from Longitudinal Income Tax Data, Miles Corak and Andrew Heisz (October, 1998)

No. 114 Foreign-Born vs Native-Born Canadians: A Comparison of Their Inter-Provincial Labour Mobility, Zhengxi Lin (September 1998)

No. 115 Living Arrangements and Residential Overcrowding: the situation of older immigrants in Canada, 1991, K.G. Basavarajappa (September 1998)

No. 116 What is Happening to Earnings Inequality and Youth Wages in the 1990s? Garnett Picot (July 1998)

No. 117 The Determinants of the Adoption Lag for Advanced Manufacturing Technologies, John R. Baldwin and Mohammed Rafiquzzaman (August 1998)

No. 118 Labour Productivity Differences Between Domestic and Foreign-Controlled Establishments in the Canadian Manufacturing Sector, John R. Baldwin and Naginder Dhaliwal (March 1, 2000)

No. 119 Technology Adoption: A Comparison Between Canada and the United States, John R. Baldwin and David Sabourin (August 1998) 
No. 120 Are There High-Tech Industries or Only High-Tech Firms? Evidence From New Technology-Based Firms, John R. Baldwin and Guy Gellatly (December 1998)

No. 121 A Portrait of Entrants and Exits, John R. Baldwin (June 1999)

No. 122 Determinants of Innovative Activity in Canadian Manufacturing Firms: The Role of Intellectual Property Right, John R. Baldwin, Petr Hanel and David Sabourin (March 7, 2000)

No. 123 In progress (John Baldwin)

No. 124 New Views on Inequality Trends in Canada and the United States, Michael C. Wolfson and Brian B. Murphy (August 1998 and October 1999 (paper))

No. 125 Employment Insurance in Canada: Recent Trends and Policy Changes, Zhengxi Lin (September 1998)

No. 126 Computers, Fax Machines and Wages in Canada: What Really Matters?, René Morissette and Marie Drolet (October 1998)

No. 127 Understanding the Innovation Process: Innovation in Dynamic Service Industries, Guy Gellatly and Valerie Peters (December 1999)

No. 128 Recent Canadian Evidence on Job Quality by Firm Size, Marie Drolet and René Morissette (November 1998)

No. 129 Distribution, Inequality and Concentration of Income Among Older Immigrants in Canada, 1990, K.G. Basavarajappa (April 1999)

No. 130 Earnings Dynamics and Inequality among Canadian Men, 1976-1992: Evidence from Longitudinal Income Tax Records, Michael Baker and Gary Solon (February 1999)

No. 131 The Returns to Education, and the Increasing Wage Gap Between Younger and Older Workers, C. Kapsalis, R. Morissette and G. Picot (March 1999)

No. 132 Why Do Children Move Into and Out of Low Income: Changing Labour Market Conditions or Marriage and Divorce?, G. Picot, M. Zyblock and W. Pyper (March 1999)

No. 133 Rising Self-Employment in the Midst of High Unemployment: An Empirical Analysis of Recent Developments in Canada, Zhengxi Lin, Janice Yates and Garnett Picot (March 1999)

No. 134 The Entry and Exit Dynamics of Self-Employment in Canada, Zhengxi Lin, Garnett Picot and Janice Yates (March 1999)

No. 135 Death and Divorce: The Long-term Consequences of Parental Loss on Adolescents, Miles Corak (June 9, 1999)

No. 136 In progress (Frank Jones)

No. 137 Innovation, Training and Success, John Baldwin (October 1999)

No. 138 The Evolution of Pension Coverage of Young and Older Workers in Canada, René Morissette and Marie Drolet (December 1999)

No. 139 Import Competition and Market Power: Canadian Evidence, Aileen J. Thompson (April 2000)

No. 140 In Progress 
No. 141 In Progress

No. 142 In Progress

No. 143 Differences in Innovator and Non-Innovator Profiles: Small Establishments in Business Services, Guy Gellatly (December 1999)

No. 144 Social Transfers, Earnings and Low-Income Intensity Among Canadian Children, 1981-1996: Highlighting Recent Development in Low-Income Measurement, John Myles and Garnett Picot (March 2000)

No. 145 In Progress

No. 146 To What Extent Are Canadians Exposed to Low-Income?, René Morissette and Marie Drolet (April, 2000)

No. 147 The Maturation of Canada's Retirement Income System: Income Levels, Income Inequality and Low-Income among the Elderly, John Myles (March 6, 2000)

No. 148 The Performance of the 1990s Canadian Labour Market, Garnett Picot and Andrew Heisz (April, 2000)

No. 149 In Progress

No. 150 Patterns of Corporate Diversification in Canada: An Empirical Analysis, John R. Baldwin, Desmond Beckstead, Guy Gellatly and Alice Peters (June 2000)

No. 151 Multinationals and the Canadian Innovation Process, John R. Baldwin and Petr Hanel (June, 2000) 